
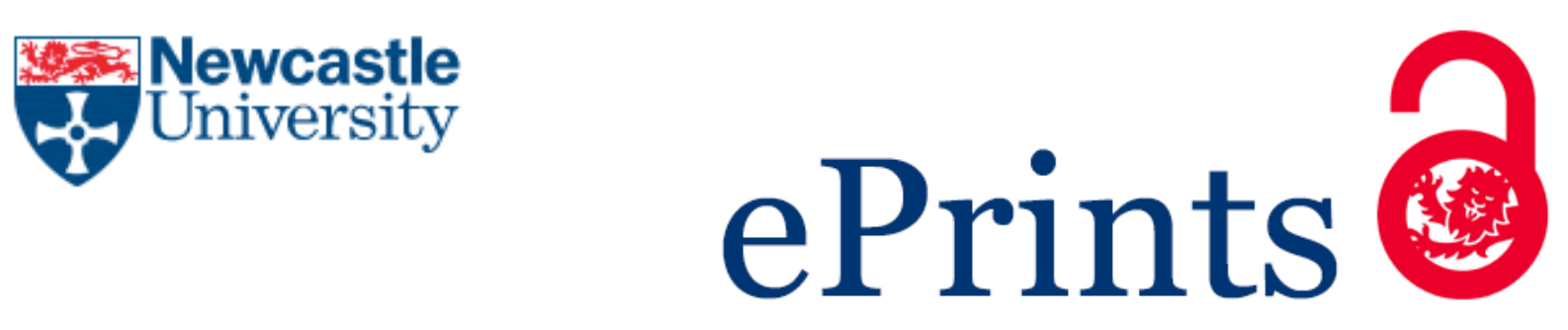

\author{
Notini L, Latta DE, Neumann A, Pearce Cl, Sassi M, N'Diaye AT, Rosso KM, \\ Scherer MM. The Role of Defects in Fe(II)-Goethite Electron Transfer. \\ Environmental Science \& Technology 2018, 52(5), 2751-2759.
}

\title{
Copyright:
}

This document is the Accepted Manuscript version of a Published Work that appeared in final form in Environmental Science \& Technology, copyright (C) American Chemical Society after peer review and technical editing by the publisher. To access the final edited and published work see https://doi.org/10.1021/acs.est.7b05772

DOI link to article:

https://doi.org/10.1021/acs.est.7b05772

Date deposited:

$17 / 03 / 2018$

Embargo release date:

06 February 2019 
'Department of Civil and Environmental Engineering, University of Iowa, Iowa City, IA, 52242,

${ }_{2}^{2}$ School of Engineering, Newcastle University, Newcastle upon Tyne, NE1 7RU, United

Luiza Notini', Drew E. Latta', Anke Neumann², Carolyn I. Pearce ${ }^{3}$, Michel Sassi' ${ }^{3}$, Alpha T. $\mathrm{N}^{\prime}$ Diaye $^{4}$, Kevin M. Rosso ${ }^{3}$, and Michelle Scherer ${ }^{1 *}$ Kingdom.

3Pacific Northwest National Laboratory, Richland, WA 99352, United States

${ }^{4}$ Advanced Light Source, Lawrence Berkeley National Laboratory, Berkeley, CA 94720

*Corresponding author: Tel.: 319.335.5654; Fax: 319.335.5660; E-mail: michellescherer@uiowa.edu 
Despite substantial experimental evidence for $\mathrm{Fe}(\mathrm{II})-\mathrm{Fe}(\mathrm{III})$ oxide electron transfer, computational chemistry calculations suggest that oxidation of sorbed Fe(II) by goethite is kinetically inhibited on structurally perfect surfaces. Here we used a combination of ${ }^{5} \mathrm{Fe}$ Mössbauer spectroscopy, synchrotron X-ray absorption, and magnetic circular dichroism (XAS/XMCD) spectroscopies supported by density functional theory calculations to investigate whether Fe(II)-goethite electron transfer is influenced by defects. Specifically, Fe L-edge and O $\mathrm{K}$-edge XAS indicates that the outermost few Angstroms of goethite synthesized by low temperature $\mathrm{Fe}(\mathrm{III})$ hydrolysis is iron deficient relative to oxygen. Corresponding XMCD shows that this non-stoichiometric surface displays uncompensated octahedral $\mathrm{Fe}^{3+}$ that is weakly ferrimagnetic. This non-stoichiometric goethite undergoes facile Fe(II)-Fe(III) oxide electron transfer, depositing additional goethite consistent with experimental precedent. Hydrothermal treatment of this goethite at $150{ }^{\circ} \mathrm{C}$, however, imparts bulk stoichiometry and antiferromagnetism at the surface. Hydrothermal treatment decreases the amount of $\mathrm{Fe}$ (II) oxidation, and changes the composition of the oxidation product. When hydrothermally treated goethite was ground, surface defect characteristics as well as the extent of electron transfer were largely restored. We propose that $\mathrm{Fe}$ vacancies comprise the defects that enable electron transfer by providing sites into which $\mathrm{Fe}(\mathrm{II})$ can strongly bind and be oxidized by the lattice, depositing $\mathrm{Fe}(\mathrm{III})$ that propagates the goethite structure. Our findings suggest that surface defects play a commanding role in $\mathrm{Fe}(\mathrm{II})-$ goethite redox interaction, as predicted by computational chemistry. Moreover, it suggests that, in the environment, the extent of this interaction, which also likely underlies $\mathrm{Fe}(\mathrm{II})$-catalyzed recrystallization and trace element release and incorporation, will vary depending on diagenetic history, local redox conditions, as well as being subject to regeneration via seasonal fluctuations.

\section{TABLE OF CONTENTS ART}
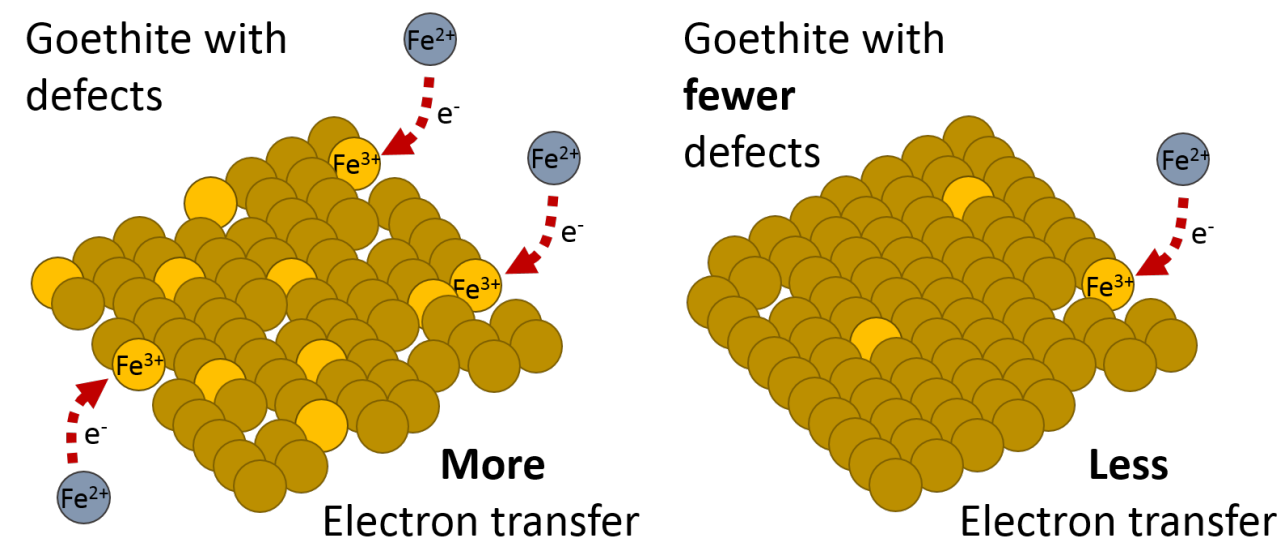
Ferrous and ferric iron comprise one of the most abundant redox couples, and electron transfer between these two oxidation states controls the cycling and availability of Fe in water, soil, and air. ${ }^{1,2}$ Over the last decade significant evidence has accumulated to demonstrate interfacial electron transfer between sorbed $\mathrm{Fe}(\mathrm{II})$ and $\mathrm{Fe}$ (III) in Fe oxides and $\mathrm{Fe}$-containing clay minerals. ${ }^{3-15}$ In some cases, electron transfer also appears to be followed by mixing of $\mathrm{Fe}$ atoms from the bulk mineral structure with the surrounding fluid (also termed $\mathrm{Fe}$ (II)-catalyzed recrystallization).$^{10.1623}$ While $\mathrm{Fe}(\mathrm{II})-\mathrm{Fe}(\mathrm{III})$ electron transfer and mixing have been clearly demonstrated, a mechanistic understanding of these reactions remains elusive. Knowledge gaps in our understanding of $\mathrm{Fe}(\mathrm{II})-\mathrm{Fe}$ (III) reaction mechanisms limit our ability to reliably predict important environmental and geochemical processes, such as cycling of $\mathrm{C}, \mathrm{N}$, and $\mathrm{P}{ }^{2+29}$ water treatment ${ }^{30}$ contaminant remediation, ${ }^{3,34}$ metal cycling, ${ }^{1,3.35}$ mineral transformations, ${ }^{36}$ and interpreting the ancient rock record..$^{37}$

Thus far, $\mathrm{Fe}$ (II)-Fe(III) electron transfer has been demonstrated for several $\mathrm{Fe}$ oxides, including hematite, goethite, magnetite, ferrihydrite, as well as Fe-containing clay minerals. ${ }^{3.15}$ Of the Fe minerals, electron transfer between Fe(II) and goethite has been the most extensively studied. Oxidation of $\mathrm{Fe}(\mathrm{II})$ by goethite has been shown to occur over a range of $\mathrm{Fe}(\mathrm{II})$ concentrations, amounts of Al-substitution, and in the presence of various anions, such as phosphate, bicarbonate, silicate and organic matter. ${ }^{3.4 .6,8.101 .2 .16,1.17}$

Despite abundant experimental evidence for $\mathrm{Fe}(\mathrm{II})-\mathrm{Fe}(\mathrm{III})$ oxide electron transfer, computational evidence suggests that $\mathrm{Fe}$ (II)-goethite electron transfer is not energetically favored on structurally perfect surfaces ${ }^{3 \times 40}$ For example, density functional theory (DFT) calculations of $\mathrm{Fe}(\mathrm{II})$ adsorbed onto charge neutral, stoichiometric goethite (110) surfaces suggest that the oxidation of sorbed $\mathrm{Fe}$ (II) by lattice Fe(III) is energetically uphill. Others similarly conclude that charge only minimally delocalizes between Fe(II) and surface Fe(III), with only a minor dependence on the type of $\mathrm{Fe}$ (II)-mineral complex formed. ${ }^{3,40}$ Additionally, a recent molecular dynamics study examining the electron transfer kinetics for stable inner and outer-sphere $\mathrm{Fe}$ (II) complexes on a wide range of perfect goethite terminations showed that the energetics are at best only thermoneutral, with large activation energies."

Each of these studies, however, suggest or infer that surface defects may underlie the experimentally observed interfacial electron transfer ${ }^{3 \times+0}$ For example, calculations simulating an oxygen vacancy on goethite (110) showed that electron transfer to the resulting lowercoordinated Fe(III) was more energetically favorable and less kinetically inhibited. This idea is conceptually similar to the notion that defects provide traps in the interior of the solid for excess electrons to accumulate. ${ }^{942}$ Given these computational findings, experiments designed to test the prospective role of defects could help advance our mechanistic understanding of $\mathrm{Fe}$ (II)-Fe(III) oxide electron transfer.

Defects arise from a deviation in the perfect composition and/or structure of a mineral.

91 Such features are common in goethite ${ }^{3+4 t}$ and have been previously studied in terms of their

92 relationship to growth conditions, ${ }^{4,3,4,4,48}$ including non-classical growth pathways such as 
imperfect oriented attachment..$^{4951}$ The type and concentration of defects strongly influence

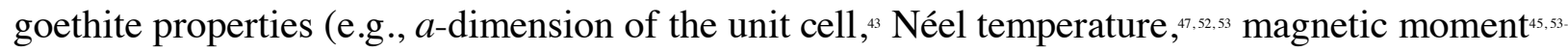
${ }^{s s}$ ) and particle reactivity (e.g., dissolution rates and ion sorption). Defects in the ideal goethite stoichiometry (i.e., $\alpha-\mathrm{FeOOH})$ can take the form of iron or oxygen vacancy, but often can be characterized as an excess of water/hydroxyl relative to the theoretical formula ${ }_{, 4}^{46}$ such that the effective formula is $\alpha-\mathrm{Fe}_{1, y 3} \mathrm{O}_{1, y}(\mathrm{OH})_{1+y}{ }^{43}$ Changes in goethite properties after hydrothermal treatment have been interpreted to be due to removal of defects. ${ }^{3,4,4,56}$ Conversely, ball-milling has been suggested to add defects to goethite based on observed changes in the Néel temperature.45

While there is clear evidence that defects are often present in goethite, little is known about how defects influence Fe(II)-goethite electron transfer. To date, no experimental data has been presented that specifically evaluates the role of defects in $\mathrm{Fe}(\mathrm{II})$-goethite electron transfer, despite significant speculation about their role in enabling electron transfer and driving Fe(II)catalyzed Fe oxide recrystallization. ${ }^{19,21,38-40}$ Here we provide the first experimental evidence that shows defects influence the extent of $\mathrm{Fe}(\mathrm{II})$-goethite electron transfer and the composition of the product formed. Our findings indicate that low temperature Fe(III) hydrolysis results in goethite particles that have excess hydroxyl/water content and corresponding Fe vacancies that enable $\mathrm{Fe}$ (II)-goethite electron transfer. Hydrothermally treating the goethite particles appears to remove defects, inhibit $\mathrm{Fe}(\mathrm{II})$-goethite electron transfer, and alter the composition of the oxidation product. Our findings suggest that surface defects play an important role in $\mathrm{Fe}$ (II)goethite redox interaction, as predicted by computational chemistry.

\section{METHODS}

Oxide Synthesis. Goethite was prepared from ${ }^{\circ} \mathrm{Fe}$-enriched Fe metal ((Isoflex, 99.94\% purity), ${ }^{5 \mathrm{Fe}}$ goethite) by modifying the Schwertmann and Cornell method, using iron metal as the synthesis' starting point instead of $\mathrm{Fe}\left(\mathrm{NO}_{3}\right)_{3}{ }^{5}{ }^{5} \mathrm{Briefly},{ }^{5} \mathrm{Fe}(0)$ was dissolved in $\mathrm{HCl}$ to obtain 15 $\mathrm{mL}$ of an $\mathrm{Fe}(\mathrm{II})$ stock $(\sim 0.6 \mathrm{M} \mathrm{Fe}(\mathrm{II}), \sim 1.8 \mathrm{M} \mathrm{HCl})$, and the solution was oxidized using $2 \mathrm{~mL}$ of $30 \%$ (slight excess) $\mathrm{H}_{2} \mathrm{O}_{2}$ to produce $\mathrm{Fe}(\mathrm{III})$. Then, the $\mathrm{pH}$ was raised with $16 \mathrm{~mL}$ of $5 \mathrm{M} \mathrm{KOH}$ and the resulting precipitate was placed in an oven at $70{ }^{\circ} \mathrm{C}$ for 60 hours. ${ }^{\circ} \mathrm{Fe}$ goethite was washed, centrifuged, freeze dried, ground with a mortar and pestle, and passed though a 100 mesh sieve. The final mineral is referred to as "as-synthesized" and it is similar to the

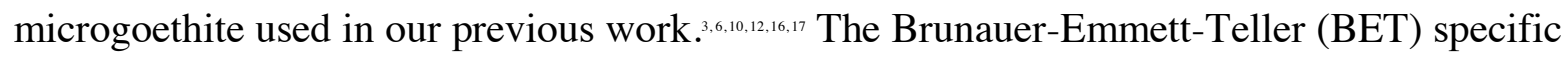
surface area was determined by $\mathrm{N}_{2}$ soprtion at $77 \mathrm{~K}$ and found to be 28 to $34 \mathrm{~m}^{2} \mathrm{~g}^{-1}$. X-ray diffraction (XRD - Rigaku Mini FlexII) patterns showed that the material contains goethite and no other minerals (Figure S7).

Electron Transfer Experiments. All experiments were carried out in an anaerobic glovebox with $\mathrm{N}_{2} / \mathrm{H}_{2}$ atmosphere (93/7\%), and all solutions were purged at least 2 hours with $\mathrm{N}_{2}$ prior to trasfer into the glovebox. Fe(II) stock solutions were prepared inside the glovebox by reacting ${ }^{s} \mathrm{Fe}$ metal (Cambridge Isotope, $96.93 \%$ purity) with $1 \mathrm{M} \mathrm{HCl}$ overnight. The resulting solution was filtered to remove any residual $\mathrm{Fe}(0)$ and diluted with deionized (DI) water to the desired concentration $(\sim 100 \mathrm{mM} \mathrm{Fe}(\mathrm{II}), \sim 0.1 \mathrm{M} \mathrm{HCl})$. 
Batch reactors were prepared by adding $10 \mathrm{~mL}$ of $25 \mathrm{mM}$ HEPES (4-(2-hydroxyethyl)-1piperazineethanesulfonic acid), $\mathrm{p} K_{a} 7.55^{\text {s) }}$ ) buffer adjusted to $\mathrm{pH} 7.5 \pm 0.05$ plus $25 \mathrm{mM} \mathrm{KBr}$ electrolyte to a $20 \mathrm{~mL}$ glass vial and adding Fe(II) stock to reach an initial ${ }^{s} \mathrm{Fe}$ (II) concentration of $\sim 1 \mathrm{mM}$. The reaction was started by adding $20.0 \pm 0.2 \mathrm{mg}$ of ${ }^{5} \mathrm{Fe}$ goethite and the reactors were placed on a end-over-end rotator in the absence of light. The aqueous phase was filtered $(0.2 \mu \mathrm{m})$ and acidified with trace metal grade $\mathrm{HCl}$ for subsequent $\mathrm{Fe}(\mathrm{II})$ and total $\mathrm{Fe}$ analysis using the 1,10-phenanthroline method..$^{\circ}$

Extraction. Two additional reactors were prepared by reacting si $\mathrm{Fe}$ goethite with ${ }^{s} \mathrm{Fe}(\mathrm{II})$, and the reacted solids were centrifuged and then extracted to remove the sorbed $\mathrm{Fe}$ species. The first reactor was extracted with a $0.4 \mathrm{M} \mathrm{HCl}$ (15 minutes). For the second reactor, the reacted solids were subjected to a sequential extraction procedure using HEPES buffer ( $\mathrm{pH} 7.5,1$ hour) followed by $1 \mathrm{M} \mathrm{CaCl}_{2}$ (pH 7, 4 hours) and $1 \mathrm{M} \mathrm{NaH}_{2} \mathrm{PO}_{4}$ (pH 5, 18 hours). A 30 min wash step with DI water was carried out after the $\mathrm{CaCl}_{2}$ and $\mathrm{NaH}_{2} \mathrm{PO}_{4}$. The extracted solids were analyzed by Mössbauer spectroscopy and the extracted aqueous phase were analyzed for $\mathrm{Fe}(\mathrm{II})$ and total Fe.

Hydrothermal treatment. Goethite was subjected to a hydrothermal treatment to anneal defects. A suspension of the as-synthesized ${ }^{\circ} \mathrm{Fe}$ goethite in deionized water was placed into a digestion bomb, and kept in an oven at $150^{\circ} \mathrm{C}$ for 44 hours. The digestion bomb was allowed to cool down and the solids were centrifuged and freeze dried (refered to as hydrotermally treated goethite). The batch of hydrothermally treated goethite was split in two, and part of it was reacted with $1 \mathrm{mM} s \mathrm{Fe}(\mathrm{II})$ as discussed above. The other part was crushed with mortar and pestle to restore defects (referred to as ground goethite). Again, the batch was split, and part was reacted with $1 \mathrm{mM}{ }^{5} \mathrm{Fe}(\mathrm{II})$, while the other aliquot was hydrothermally treated again under the same conditions, and then reacted with $1 \mathrm{mM}{ }^{s} \mathrm{Fe}$ (II) (refered as hydrothermally treated again goethite).

Samples of goethite after sequetial treatments were characterized by XRD, scanning electron microscopy (SEM - Hitachi S-4800), transmission electron microscopy (TEM - JEOL JEM 1230), X-ray absorption spectroscopy (XAS) and X-ray magnetic circular dichroism spectroscopy (XMCD).

Mössbauer spectroscopy. For Mössbauer spectroscopy, solids were collected on a 0.2 $\mu \mathrm{m}$ nitrocelulose filter and than sealed between two pieces of Kapton tape to avoid air oxidation. Mössbauer spectra were collected at $77 \mathrm{~K}$ on a spectrometer supplied by Web Research, Inc. (Edina, Minnesota, USA) and equipped with closed-cycle cryostat (CCS-850 System, Janis Research Co., Wilmington, Massachusetts, USA). We acquired spectra in transmission mode using a constant acceleration drive system and a ${ }^{s} \mathrm{Co}$ source. The velocity scale was calibrated using a $7-\mu \mathrm{m} \alpha-\mathrm{Fe}(0)$ foil. We fit the spectra using the software Recoil (Ottawa, Canada). ${ }^{\infty}$

Selected samples were reanalyzed after atmosphere exposure. After initial Mössbauer analysis, these samples were stored for a month in normal atmosphere and then reanalyzed by Mössbauer spectroscopy. For comparison, one sample was kept inside the anaerobic glovebox for the same time span. 
174 For X-ray absorption spectroscopy, suspensions of goethite were dropped onto indium foil in an anaerobic glovebox with $\mathrm{N}_{2} / \mathrm{H}_{2}$ atmosphere $(93 / 7 \%)$, dried, then pressed into the foil and the excess solid was removed. The indium foil was attached to the copper sample manipulator with silver paint. XAS and XMCD measurements were performed using Beamline 6.3.1.1 at the Advanced Light Source (Berkeley, CA). $\mathrm{Fe} \mathrm{L}_{23}$-edge and $\mathrm{O} \mathrm{K}$-edge XAS were recorded at room temperature in total electron yield mode; $\mathrm{Fe}_{2,3}$-edge XAS has an effective probing depth of 50 $\AA$. Fe $\mathrm{L}_{2,3}$-edge XMCD spectra were obtained by measuring two XAS spectra with a fixed degree of circular polarization of $\sim 0.7$ and with opposing magnetization directions by reversing the applied field of $1.8 \mathrm{~T}$ at each energy point. The XAS spectra were normalized to incident beam intensity, and the XMCD spectrum was obtained as the difference between the two spectra.

Density Functional Theory Computations. We used the FDMNES code ${ }^{61}$ to individually calculate the O K-edge XANES spectra of the two oxygen sites present in goethite, explicitly taking into account their respective local coordination environments in the bulk structure. The Green's formalism approach, within the limit of the muffin-tin approximation, was used. The Fermi energy has been determined self-consistently using an aggregate of radii of $7 \AA$. A cluster of $7 \AA$ radii has also been used to perform the final state calculations. The HedinLundquist potentials ${ }^{62}$ were used to model the exchange-correlation. Dipoles, core-hole contributions and spin-orbit coupling were taken into account. Because the experimental spectra of goethite is made of two components with unknown relative position and intensity, we have used a non-negative least square algorithm to refine the position and intensity of the two calculated $\mathrm{O}^{2}$ and $\mathrm{OH}$ component spectra, and have found the best linear combination that would fit the experimental spectra. The resulting linear combination fit of the measured $\mathrm{O} \mathrm{K}$-edge spectra with the computed component spectra for $\mathrm{O}^{2}$ and $\mathrm{OH}$ was used to quantify relative contributions of these two oxygen species.

\section{RESULTS AND DISCUSSION}

Fe(II)-Goethite Electron Transfer. To explore if defects influence Fe(II)-goethite electron transfer, we ran a series of Fe isotope labeled experiments with as-synthesized and hydrothermally treated goethite particles. Similar to our previous work ${ }^{3,5,6,10-12,14}$, we took advantage of the element and isotope specificity of ${ }^{57} \mathrm{Fe}$ Mössbauer spectroscopy to track if Fe(II)-goethite electron transfer occurs. Here, we treated Mössbauer-invisible ${ }^{5} \mathrm{Fe}$ goethite with a sequence of hydrothermal treatment and grinding steps in an attempt to remove or add defects, presumably at surfaces, and then reacted the goethite with $1 \mathrm{mM}{ }^{5} \mathrm{Fe}(\mathrm{II})$ and collected ${ }^{{ }^{5} \mathrm{Fe}}$ Mössbauer spectra of the filtered solids to determine if sorbed Fe(II) was oxidized (Figure 1). The ${ }^{5} \mathrm{Fe}$ Mössbauer spectra of the reacted solids revealed two prominent Fe(III) sextets consistent with goethite and suggest that substantial oxidation of ${ }^{5} \mathrm{Fe}$ (II) occurred and formed ${ }^{57}$ goethite on both the assynthesized goethite and the hydrothermally treated goethite (Table S1). Oxidation of sorbed $\mathrm{Fe}(\mathrm{II})$ by goethite is consistent with our and others' previous work., $3,6,8,10,12$ 
After reaction with ${ }^{s} \mathrm{Fe}(\mathrm{II})$, there is, however, a marked difference between the as-synthesized goethite and the hydrothermally treated goethite. The Fe(III) sextets capture a smaller portion of the spectral area of the hydrothermally treated compared to the as-synthesized goethite (as shown by blue sextets in Figure 1a and b). To test if the change in spectral area distribution upon hydrothermal treatment was reversible, we ground the hydrothermally treated goethite particles and reacted them with ${ }^{s} \mathrm{Fe}(\mathrm{II})$. The resulting spectrum shows a marked increase in the amount of area captured by the sextet (and less hatched area) (Figure 1c). A second hydrothermal treatment returned the spectrum of Fe(II)-reacted solids to one similar to that of the first hydrothermal treatment (Figure 1d). To test that the change in spectral area trend observed in Figure 1 was not particular to a goethite synthesis batch, we ran duplicates of each treatment using two separate batches of goethite (Figure S1). The similarity of the duplicate experiments conducted with two separately synthesized goethite batches provides strong evidence that hydrothermal treatment and grinding are reproducibly altering the goethite in a way that influences how it reacts with $\mathrm{Fe}(\mathrm{II})$.

The reversible, reproducible changes in the Mössbauer spectra indicate that hydrothermal treatment and grinding are influencing the product formed from ${ }^{5} \mathrm{Fe}$ (II) interaction with goethite. To fit the hatched area in the Mössbauer spectra we tried a variety of approaches. We concluded that the best method to capture the hatched area was to include an Fe(II) doublet and a broad, collapsed sextet consistent with our and other's previous approach (for more details see SI and Figure S2) ${ }^{10.03}$ Small Fe(II) doublets comprising less than $10 \%$ of the total area have been previously observed in spectra of goethite reacted with ${ }^{35} \mathrm{Fe}(\mathrm{II})$, $, 10,2 \mathrm{r}^{\mathrm{s}}$ but little is known about the composition of the broad, collapsed sextet and we have, in our previous work, been careful to not interpret it beyond that it was likely Fe(III). ${ }^{10}$ To check whether that the collapsed feature was influenced by buffer-Fe interactions ${ }^{\star}$, we ran a control experiment without buffer (Figure S4). There was no difference between the spectra of the buffered and un-buffered samples indicating that the buffer-Fe interactions were not responsible for the collapsed feature.

To investigate the composition of the collapsed feature, we subjected the as-synthesized goethite particles reacted with ${ }^{\mathrm{F}} \mathrm{Fe}(\mathrm{II})$ to different extraction procedures and collected Mössbauer spectra afterwards (Figure 2). A mild $\mathrm{HCl}$ extraction $(0.4 \mathrm{M})$ removed both the $\mathrm{Fe}$ (II) doublet and the broad, collapsed sextet from the Mössbauer spectra. All of the Fe(II) that had initially sorbed was recovered in the $\mathrm{HCl}$ extract (Table S2). Surprisingly, the aqueous extract from the $\mathrm{HCl}$ treatment contained only $\mathrm{Fe}(\mathrm{II})$, suggesting that the collapsed feature was at least partially due to $\mathrm{Fe}(\mathrm{II})$. To minimize the change in $\mathrm{pH}$ during extraction, we also extracted goethite reacted with ${ }^{5} \mathrm{Fe}$ (II) with $\mathrm{CaCl}_{2}$ and $\mathrm{NaH}_{2} \mathrm{PO}_{4}$ which only decreased the $\mathrm{pH}$ to 7 and 5 , respectively. Similar to the $\mathrm{HCl}$ extraction, the milder extractions removed most of the collapsed feature and recovered similar amounts of $\mathrm{Fe}$ (II) (for additional discussion see SI and Figure S5).

As an alternative approach to evaluate whether the collapsed feature contains $\mathrm{Fe}(\mathrm{II})$, we oxidized a sample of goethite reacted with ${ }^{5} \mathrm{Fe}(\mathrm{II})$ to see if the collapsed feature disappeared. One month of air exposure resulted in complete removal of the collapsed feature and the $\mathrm{Fe}(\mathrm{II})$ doublet from the spectra, providing an additional line of evidence that the collapsed feature 
contained some Fe(II) (Figure 2). The spectra of the oxidized goethite, however, looks slightly different than the spectra of the $\mathrm{HCl}$-extracted goethite, in which a third sextet appeared. The third sextet was identified as akaganéite, a mineral typically formed by the hydrolysis of $\mathrm{Fe}(\mathrm{III})$ salts in the presence of $\mathrm{Cl}^{65}$ Regardless of the precise identity of the collapsed feature, the oxidation and extraction data combined provide compelling evidence that the collapsed feature contains some $\mathrm{Fe}$ (II) and is more likely a mixed $\mathrm{Fe}$ (II)-Fe(III) phase rather than a pure $\mathrm{Fe}$ (III) phase as we previously thought. ${ }^{10}$ While we cannot rule out that it is a pure Fe(II) phase, the Mössbauer parameters of the collapsed sextet are more consistent with a mixed $\mathrm{Fe}(\mathrm{II})-\mathrm{Fe}(\mathrm{III})$ compound (further discussed in Supporting Information) ${ }^{66}$ Importantly, the presence of a mixed $\mathrm{Fe}(\mathrm{II})$-Fe(III) phase rather than an $\mathrm{Fe}(\mathrm{III})$ phase suggests that some of ${ }^{s} \mathrm{Fe}(\mathrm{II})$ sorbed on goethite was not oxidized by the goethite.

To quantify the extent of sorbed Fe(II) that was oxidized to goethite as a function of surface treatment, we plotted the percent relative area of the two goethite sextets for the as-synthesized goethite and the successive hydrothermally treated and ground goethite particles (Figure 3). If one hundred percent of the spectral area was captured within the two goethite sextets, it would indicate that all of the sorbed ${ }^{~} \mathrm{Fe}$ (II) was oxidized to "goethite. Complete oxidation of $\mathrm{Fe}$ (II) did not occur in any of the samples, but instead the amount of $\mathrm{Fe}$ (II) oxidized to form goethite varied between 63 and $87 \%$ (as estimated from the relative area of the sextets). What is most striking in Figure 3, however, is how reversible and reproducible the hydrothermal and grinding treatment is in influencing the extent of oxidation of the goethite-sorbed Fe(II). The as-synthesized goethite oxidized $\approx 87 \%$ of the sorbed Fe(II) to form goethite, whereas hydrothermally treating the goethite particles resulted in only $\approx 66 \%$ of the sorbed ${ }^{5} \mathrm{Fe}$ (II) becoming oxidized to goethite, suggesting that electron transfer was inhibited by hydrothermal treatment and that the composition of the oxidation product changed. Grinding the hydrothermally treated goethite largely restored the extent of electron transfer $(\approx 81 \%)$, and hydrothermally treating this goethite sample again inhibited the extent of electron transfer $(\approx$ 63\%) (Figure 3).

Similar to the as-synthesized goethite, one month of air exposure of the hydrothermally treated goethites resulted in removal of the collapsed feature and the Fe(II) doublets from the spectra, consistent with the collapsed feature containing some Fe(II) (Figure S6). The hydrothermally treated goethites reacted with ${ }^{s} \mathrm{Fe}(\mathrm{II})$ also lost substantially more spectral area than the ground samples (as-synthesized and ground goethite), providing additional evidence that hydrothermally treating goethite leads to less oxidation of sorbed Fe(II) to goethite.

Bulk Characterization of Goethite Particles. It appears that hydrothermal treatment and grinding reversibly and reproducibly influences the extent of electron transfer from sorbed $\mathrm{Fe}$ (II) to goethite as well as the composition of the oxidation product. Given previous evidence that goethite synthesis conditions such as temperature alter the defect content in goethite, ${ }^{, 3,4}$ we hypothesized that hydrothermally treating the goethite particles at $150{ }^{\circ} \mathrm{C}$ annealed defects present in the goethite synthesized at $70^{\circ} \mathrm{C}$. We further hypothesized that grinding the particles added defects back to the hydrothermally treated particles. To evaluate if there were any changes 
in the bulk goethite particles before and after treatments, we characterized the particles with XRD, BET analysis, and microscopy. XRD spectra of treated solids confirmed that hydrothermal treatment did not transform goethite into any other mineral (Figure S7), and cell dimensions were unchanged after the goethite sequential hydrothermal/grinding treatments (Table S3). Schwertmann and collaborators observed a slight change in the $a$-axis dimension upon hydrothermal treatment, however, their initial material was a highly defective goethite. ${ }^{3}$ BET measurements revealed a small, but progressive loss in BET area (from 28 to $19 \mathrm{~m}^{2} \mathrm{~g}^{-1}$, Table S3), consistent with previous observations. . $3.4 .46^{4.6}$ In our work, TEM images revealed no substantial difference between as-synthesized and hydrothermally treated goethite, but SEM images revealed slight changes of the surface (Figure S8 and S9). Hydrothermally treated goethite appeared to have more perfectly formed ends when compared to the original mineral suggesting the hydrothermal treatment may have removed some surface defects (Figure S9).

Because hydrothermal treatment resulted in smaller BET surface area and amounts of $\mathrm{Fe}(\mathrm{II})$ sorbed, we considered the alternative hypothesis that less Fe(II)-goethite electron transfer could be simply due to less surface area and less surface-bound Fe(II) available to be oxidized. To explore whether the amount of sorbed Fe(II) influenced the extent of electron transfer, we plotted the percent relative area of the $\mathrm{Fe}(\mathrm{III})$ sextets versus sorbed $\mathrm{Fe}$ (II) per $\mathrm{m}^{2}$ (Figure 4). We binned the data into ground goethites which includes as-synthesized and ground (colored markers) and hydrothermally treated goethites which includes both rounds of hydrothermal treatment (open markers). Both ground and hydrothermally treated goethites converge to $\sim 5.5$ $\mu$ moles $\mathrm{Fe}$ (II) sorbed per $\mathrm{m}^{2}$, revealing that the sorption of $\mathrm{Fe}$ (II) was not influenced by the treatment applied to the mineral. However, it is remarkable that, when we compare a hydrothermally treated and a ground goethite that have the same amount of $\mathrm{Fe}(\mathrm{II})$ sorbed per $\mathrm{m}^{2}$, there is a marked difference $(\approx 20 \%)$ in the extent of electron transfer. Figure 4 provides compelling evidence that the changes we observed in Fe(II)-goethite electron transfer between our four treatments were not due to changes in surface area or amount of Fe(II) sorbed.

Surface Characterization of Defects on Goethite Particles. While bulk characterization of the treated goethite particles is informative, it is unlikely we would be able to detect specific changes in goethite surface structure with these techniques. To detect the presence of defects and changes in surface structure in the treated goethites, we collected X-ray absorption spectroscopy (XAS) and X-ray magnetic circular dichroism (XMCD) at the Fe L-edge and XAS at the $\mathrm{O} \mathrm{K}$-edge. By collecting total electron yield data, these techniques probe a depth no greater than $5 \mathrm{~nm}$ and are mainly sensitive to the upper few Angstroms. ${ }^{67}$ Fe L-edge XMCD spectra for all three samples is shown in Figure 5, while the illustrative O K-edge spectra and DFT-based spectral analysis are shown in Figure 6.

The Fe L-edge XAS probes the structure and valence of surface iron, whereas the XMCD is selective for the subset of surface iron that is magnetically ordered and is able to discriminate $\mathrm{Fe}$ valence and local coordination. As expected, the Fe L-edge XAS of all goethite samples measured shows features consistent with goethite $\mathrm{Fe}(\mathrm{III})$; $\mathrm{Fe}(\mathrm{II})$ is not detected (Figure S10). The corresponding XMCD information, however, is more revealing (Figure 5). The as- 
332 synthesized goethite has a weak magnetic moment at the surface (i.e., from the magnetic

333 dichroism signal intensity), and the shape of the XMCD signal is consistent with octahedrally

334 coordinated $\mathrm{Fe}(\mathrm{III}){ }^{\otimes} \mathrm{T}$ The presence of this magnetic moment indicates that the surface is magnetic,

335 likely due to $\mathrm{Fe}$ vacancies that disrupt the antiferromagnetic symmetry that would otherwise

336 exist between perfect atomic planes of goethite. ${ }^{52}$ The XMCD signal of the hydrothermally

337 treated goethite contains no distinguishable feature, indicating that the magnetic moment is

338 absent, which is consistent with the known bulk antiferromagnetic structure and the hypothesis

339 that hydrothermal treatment yields a more stoichiometric and crystalline material. After re-

340 grinding, the surface magnetic moment, and thus XMCD trace, is largely restored, consistent

341 with reintroduction of $\mathrm{Fe}$ vacancies at the surface.

342 The corresponding O K-edge XAS spectra are illustrated in Figure 6, and analyzed in more detail in the SI and Figures S11 and S12. The spectral region of primary interest is the preedge region between 530-535 eV, which is comprised of two $1 s \rightarrow 3 d$ excitation doublets, one at lower energy corresponding to $\mathrm{O}^{2}$ in the goethite surface, and one at higher energy corresponding to $\mathrm{OH}$ in the surface.9 Using DFT, we computed the specific expected shapes of these two doublets and used these theoretical components to perform linear combination fitting (LCF) of the experimentally measured O K-edge spectra for the three goethite samples. We then determined the $\mathrm{OH} / \mathrm{O}^{2}$ ratio for the surfaces of each of three goethites. Additionally, the ratio of the measured total integrated $\mathrm{Fe} \mathrm{L}$-edge and $\mathrm{O} \mathrm{K}$-edge XAS intensities were used to estimate the $\mathrm{Fe} / \mathrm{O}$ ratios in each of the three surfaces. Here we used the hydrothermally treated goethite as a normalization standard to the bulk ratio of 0.5 under the assumption that this surface is the most stoichiometric within the set. The complete surface compositional results are given in Table $\mathbf{1 .}$

The O K-edge spectra for as-synthesized, hydrothermally treated and ground goethites show that the surfaces of the as-synthesized and ground goethite are more hydrous $(\mathrm{OH}$ rich relative to $\mathrm{O}^{*}$ ) than the hydrothermally treated goethite (Figure 6 and Table 1). Note that while the bulk ideal $\mathrm{OH} / \mathrm{O}^{2}$ ratio is $50 \%$, the excitation cross-sections of the two component spectra are not necessarily equivalent such that a ratio of their integrated intensities could be expected to also correspondingly be $50 \%$; we chose not to normalize these ratios to the ideal value because the trends between samples remain the same in either case. Surfaces of as-synthesized and ground goethite bear comparably lower $\mathrm{Fe} / \mathrm{O}$ ratios relative to the hydrothermally treated goethite (Table 1), again consistent with the prevalence of Fe vacancies in these two surfaces relative to the hydrothermally treated surface.

Collectively, the observed surface compositional characteristics are consistent with the known behavior of goethite stoichiometry to vary as $\alpha-\mathrm{Fe}_{1, y 3} \mathrm{O}_{1, y}(\mathrm{OH})_{1+,}$. Due to excess protons, goethite grown at sub-hydrothermal temperatures, e.g. $70{ }^{\circ} \mathrm{C}$ as used here, tends to be both $\mathrm{Fe}$ deficient and correspondingly $\mathrm{OH}$-rich. In contrast, goethite grown hydrothermally tends to be more crystalline and stoichiometric ${ }^{43}$ Combined, the results from Mössbauer spectroscopy, XAS, and XMCD suggest that particles with fewer defects are less prone to oxidize Fe(II). We propose that the key surface defects are Fe vacancies, which provide sites into which $\mathrm{Fe}$ (II) can strongly bind and transfer electrons to lattice Fe(III), propagating a goethite-like surface. Our findings 
suggest that surface defects play a commanding role in Fe(II)-goethite redox reaction, as predicted by computational chemical modeling. ${ }^{.340}$

\section{Environmental Implications}

Here we provide the first experimental evidence that defects influence the extent of $\mathrm{Fe}(\mathrm{II})$-goethite electron transfer and the composition of the product formed. Our findings indicate that low temperature Fe(III) hydrolysis, a commonly used method for synthesizing goethite, results in goethite particles that have excess hydroxyl/water content and corresponding $\mathrm{Fe}$ vacancies that enable Fe(II)-goethite electron transfer. Hydrothermally treating the goethite particles appears to remove defects, inhibit Fe(II)-goethite electron transfer, and alter the composition of the oxidation product. The clear role of defects in enabling Fe(II)-goethite electron transfer resolves the previous discrepancy between multiple experimental observations of $\mathrm{Fe}$ (II)-goethite electron transfer ${ }^{3,4,6,8,10,1,1,1,17}$ and computational calculations that suggest $\mathrm{Fe}$ (II)goethite electron transfer is not energetically feasible on structurally perfect surfaces. ${ }^{3.40}$

Our experimental evidence that defects enable $\mathrm{Fe}(\mathrm{II})$-goethite electron transfer raises the question of whether defects influence Fe(II)-catalyzed recrystallization as we and others have proposed that $\mathrm{Fe}(\mathrm{II})-\mathrm{Fe}$ (III) interfacial electron transfer is an integral step in $\mathrm{Fe}$ (II)-catalyzed recrystallization, ${ }^{7,9,16,70,71}$ While there has been speculation that mineral surface and structural defects control $\mathrm{Fe}(\mathrm{II})$-catalyzed recrystallization ${ }^{19,21}$ experimental data to evaluate this claim is lacking. If $\mathrm{Fe}(\mathrm{II})-\mathrm{Fe}(\mathrm{III})$ oxide electron transfer controls the extent of $\mathrm{Fe}$ oxide recrystallization than our results support the hypothesis that defects play a role in $\mathrm{Fe}(\mathrm{II})$-catalyzed recrystallization. We further speculate that the removal of defects to form a more perfect surface may be the energetic driving force for Fe(II)-catalyzed recrystallization that has continued to elude us. We caution, however, that alternative mechanisms of recrystallization such as solidstate diffusion or pore/void/intergranular diffusion ${ }^{16,19}$ have not been ruled out and neither of these mechanisms are likely to be as strongly influenced by electron transfer.

The role of defects in Fe redox chemistry also provides valuable insights into the behavior of $\mathrm{Fe}$ oxides in reducing environments. If defects in the form of $\mathrm{Fe}$ deficient and $\mathrm{OH}-$ rich surfaces enable $\mathrm{Fe}(\mathrm{II})$-goethite electron transfer, then it seems reasonable to suggest that oxidative sorption of $\mathrm{Fe}(\mathrm{II})$ at the surface would fill $\mathrm{Fe}$ vacancies and anneal some surface defects. Consistent with our suggestion that oxidative sorption of Fe(II) anneals surface defects, we have previously observed less oxidation of sorbed Fe(II) by hematite at high concentrations of $\mathrm{Fe}(\mathrm{II})^{5}$ as well as reduced extents of hematite recrystallization. ${ }^{72}$ Annealing of goethite by oxidative sorption of $\mathrm{Fe}(\mathrm{II})$ followed by inhibition of electron transfer may also explain the recent report of decreased goethite recrystallization rates over time. ${ }^{20}$ Our hypothesis that oxidative sorption of Fe(II) anneals surface defects is in agreement with results that show addition of $\mathrm{Fe}(\mathrm{II})$ inhibits rates of microbial $\mathrm{Fe}(\mathrm{III})$ reduction. ${ }^{73,74}$ How defects will impact heterogeneous redox process such as contaminant reduction rates, $, 33,34,75-78$ and the observed paradoxical oxidation of As(III) at the Fe(II)-Fe oxide interface, however, remains open to experimental investigation. ${ }^{8}, 79,80$ 
Our work also shows that electron transfer between Fe(II) and goethite is sensitive to

413 diagenetic temperature and can be altered by relatively small changes in the structure. We note

414 that we were only able to observe these changes with surface-sensitive techniques (i.e., XMCD

415 and oxygen XAS). Environmental cycles that include temperature fluctuations, changes in the

416 activity of water, and redox changes can likely reinitialize electron transfer between Fe(II) and

417 goethite, and possibly restart recrystallization by controlling the defect content at the

418 goethite/water interface. The small, subtle changes needed to influence Fe(II) - goethite

419 interaction suggest that in the environment, the extent of this interaction, which also likely

420 underlies $\mathrm{Fe}(\mathrm{II})$-catalyzed recrystallization trace element release and incorporation, ${ }^{18,35,70}$ will be

421 coupled to diagenetic history, local redox conditions, and be subject to regeneration via seasonal

422 fluctuations. ${ }^{34,37}$

\section{ASSOCIATED CONTENT}

Supporting Information. Details on Mössbauer fitting, discussion on $\mathrm{HCl}$-extracted and oxidized samples as well as additional figures of fitted Mössbauer spectra, Mössbauer spectra of duplicates and extracted samples, SEM and TEM pictures and XRD spectra of the as-synthesized and treated sample. This material is available free of charge via the Internet at

\section{Corresponding Author}

432 *E-mail: michelle-scherer@uiowa.edu

\section{ACKNOWLEDGEMENTS}

This material is based upon work supported by the U.S. Department of Energy's (DOE) Office of Science, Office of Basic Energy Sciences (BES), Chemical Sciences, Geosciences, and Biosciences Division through its Geosciences program at Pacific Northwest National Laboratory (PNNL). A portion of this research was performed using EMSL, a national scientific user facility sponsored by the DOE Office of Biological and Environmental Research and located at PNNL. The work performed at the Advanced Light Source (ALS) was supported by the Director, Office of Science, BES of the DOE under Contract No. DE-AC02-05CH11231. PNNL is a multiprogram national laboratory operated for DOE by Battelle Memorial Institute under Contract No. DEAC06-76RLO-1830. Additional support for this work was provided by the National Science 
446 Table 1. Summary of surface compositional analyses of goethite from X-ray absorption 447 spectroscopy at the Fe L-edge and O K-edge, with the latter further quantified in terms of $\mathrm{O}^{2}$ and $448 \mathrm{OH}$, using linear combination fitting of the experimental spectra with DFT-based O K-edge 449 doublets.

As-synthesized $\begin{gathered}\text { Hydrothermally } \\ \text { Treated }\end{gathered} \quad$ Ground

\begin{tabular}{rccc}
\hline $\mathbf{F e} / \mathbf{O}$ & $\mathbf{0 . 2 3}$ & $\mathbf{0 . 5 0}^{*}$ & $\mathbf{0 . 2 2}$ \\
$\mathbf{O H}^{-}$ & $47.45 \%$ & $41.73 \%$ & $44.36 \%$ \\
$\mathbf{O}^{2-}$ & $52.55 \%$ & $58.27 \%$ & $55.64 \%$ \\
$\mathbf{O H} / \mathbf{O}^{2-}$ & $\mathbf{0 . 9 0}$ & $\mathbf{0 . 7 2}$ & $\mathbf{0 . 8 0}$ \\
\hline
\end{tabular}

$452 \quad(*)$ To normalize Fe/O ratios based on integrated intensities of separately collected Fe L-edge and 453 O K-edge spectra, all values were scaled proportionally by the factor needed to achieve the 454 idealized 0.50 value for the hydrothermally treated goethite. 


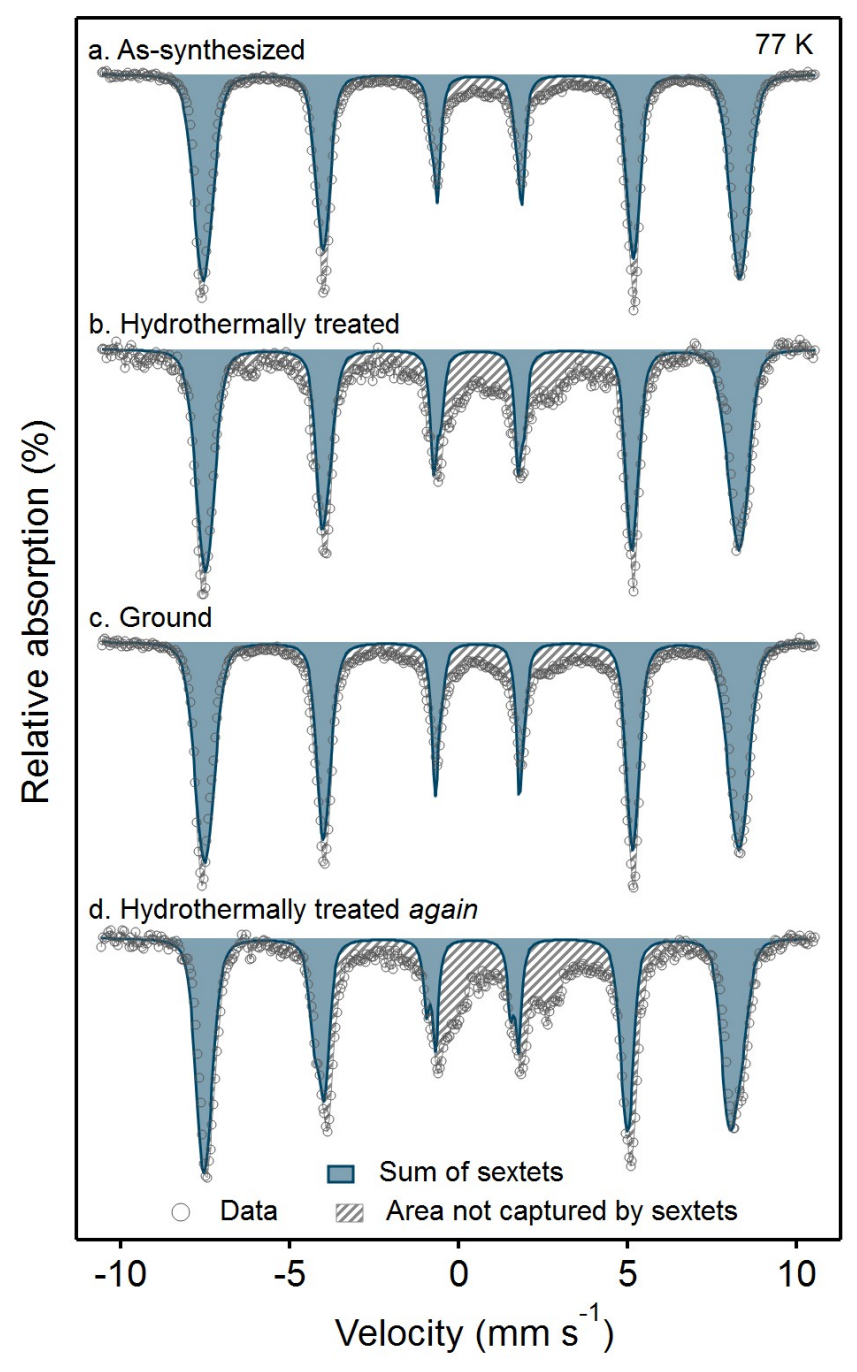

457

458

459

Figure 1. Mössbauer spectra of ${ }^{5} \mathrm{Fe}(\mathrm{II})$ reacted with ${ }^{5 \mathrm{Fe}}$ goethite after sequential 460 hydrothermal/grinding treatments. Experimental conditions: $\left[{ }^{[6} \mathrm{Gt}\right]=2 \mathrm{~g} \mathrm{~L}{ }^{-1}, 25 \mathrm{mM}$ HEPES/25 $461 \mathrm{mM} \mathrm{KBr}$ at $\mathrm{pH}$ 7.5.

462 


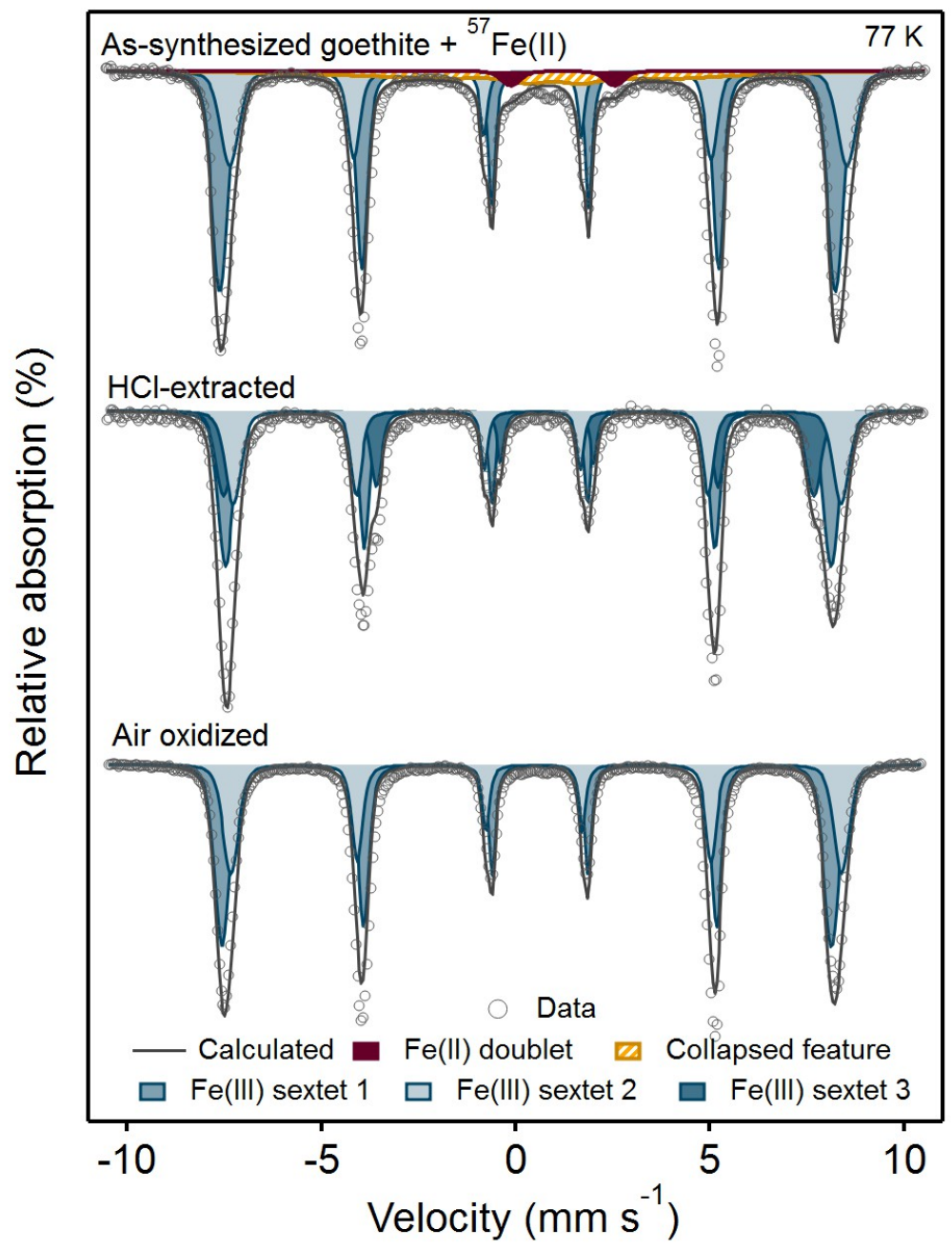

Figure 2. Mössbauer spectra of ${ }^{56} \mathrm{Fe}$ as-synthesized goethite reacted with $1 \mathrm{mM}{ }^{57} \mathrm{Fe}(\mathrm{II})$, before and after $\mathrm{HCl}$ extraction and air oxidation. Experimental conditions: $\left.{ }^{56} \mathrm{Gt}\right]=2 \mathrm{~g} \mathrm{~L}^{-1}, 25 \mathrm{mM}$ 467 HEPES/25 $\mathrm{mM} \mathrm{KBr}$ at $\mathrm{pH}$ 7.5. 


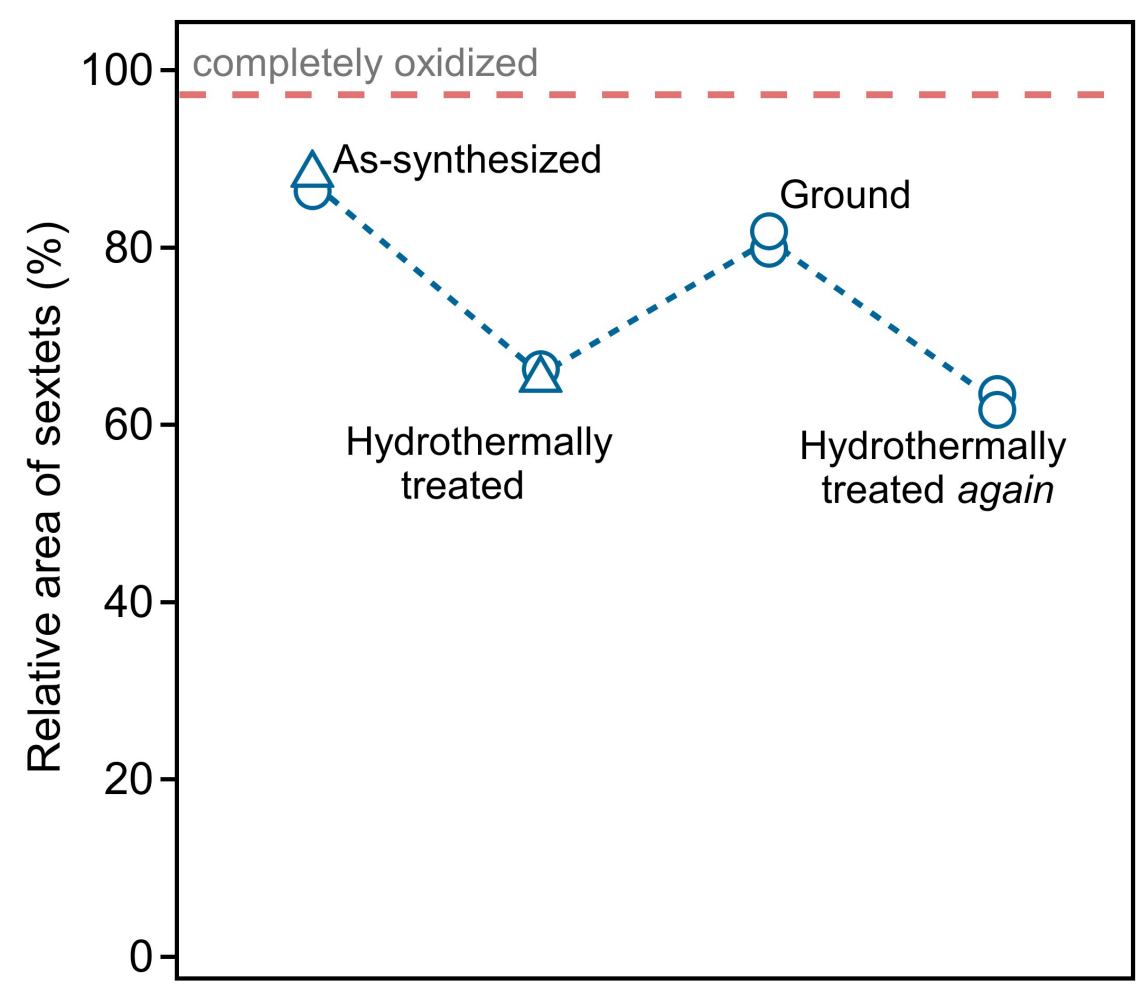

473

474

475

476

477

478

479

480

481

482

483

484

485

486

487

488

489

490

491

492
Figure 3. Relative area of $\mathrm{Fe}(\mathrm{III})$ sextets from Mössbauer spectra of ${ }^{5} \mathrm{Fe}(\mathrm{II})$ reacted with ${ }^{5 \mathrm{Fe}}$ goethite after sequential hydrothermal/grinding treatments. Percentages based on spectral fits shown in Figure S2 (data in Table S1) and described in the SI. Different markers indicate different ${ }^{5 \mathrm{Fe}}$ goethite batches. Duplicates from the same batch were hydrothermally treated/ground in separate experiments. 


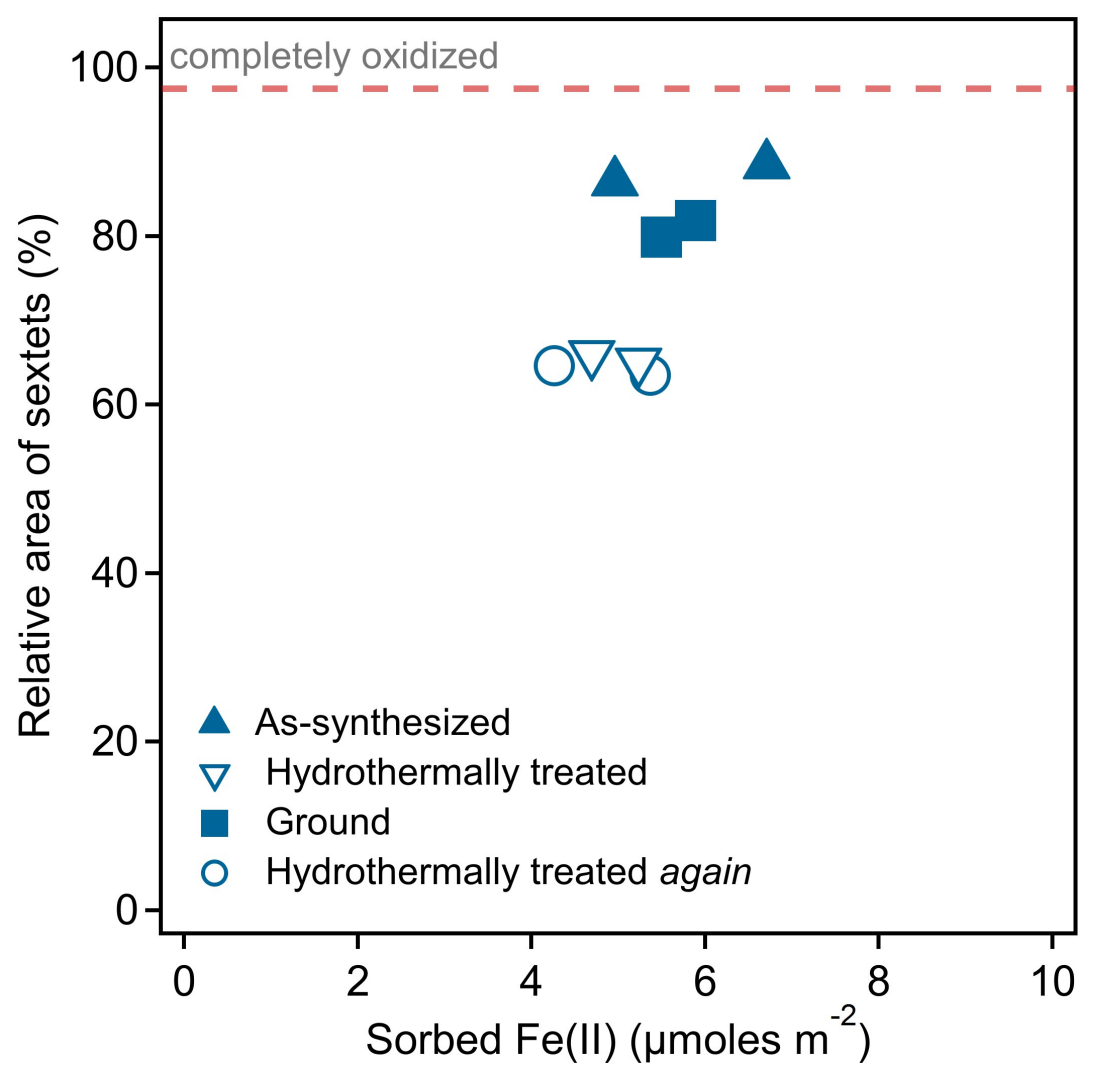

Figure 4. Relative area of Fe(III) sextets from Mössbauer spectra as a function of sorbed

$497 \mathrm{Fe}(\mathrm{II})$ per $\mathrm{m}^{2}$ for samples of ${ }^{57} \mathrm{Fe}$ (II) reacted with goethite after sequential hydrothermal/grinding 498 treatments.

499

500

501 


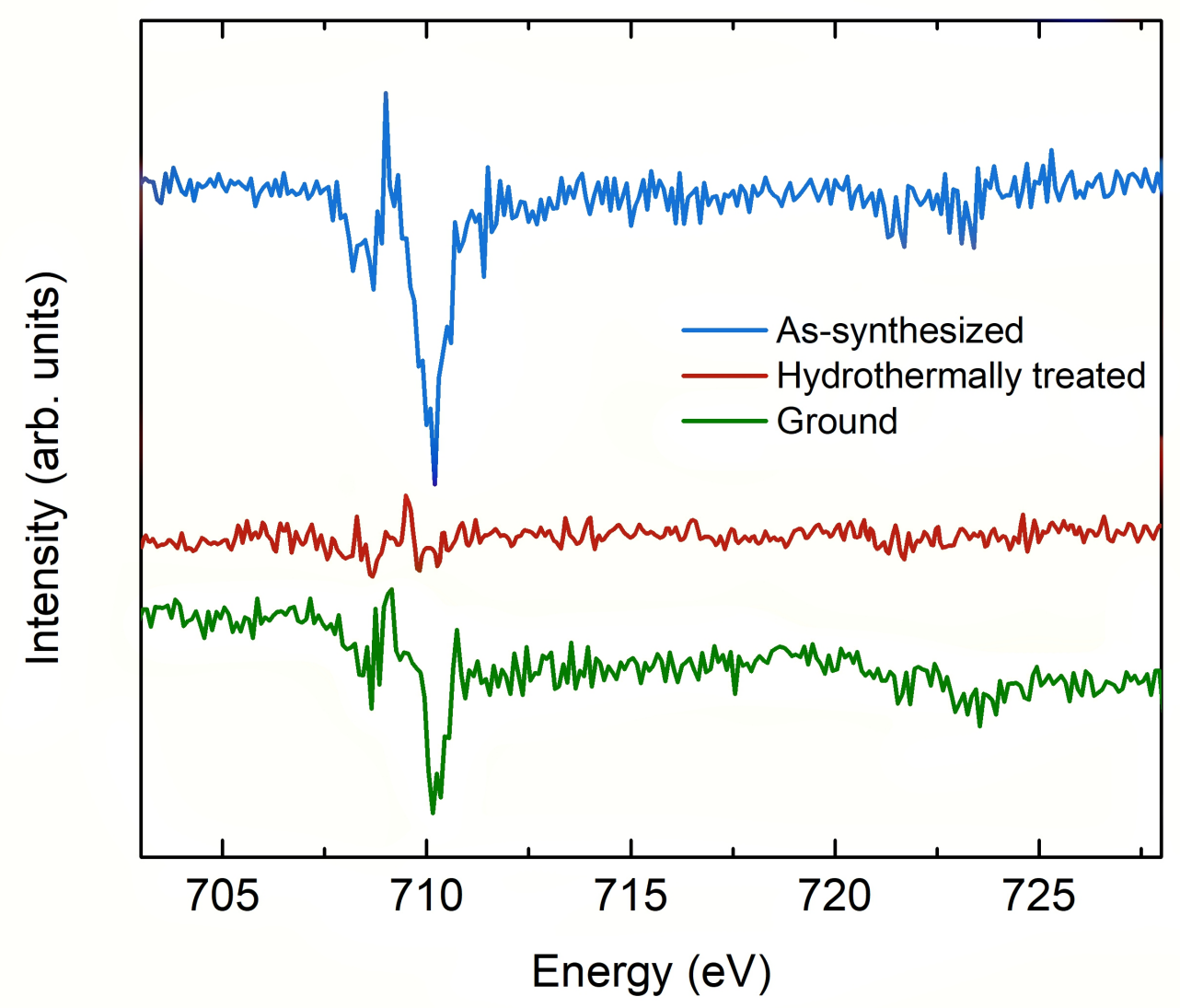

502

503

504

Figure 5. Fe L-edge XMCD of goethite after sequential hydrothermal/grinding treatments.

505

506

507

508

509

510 


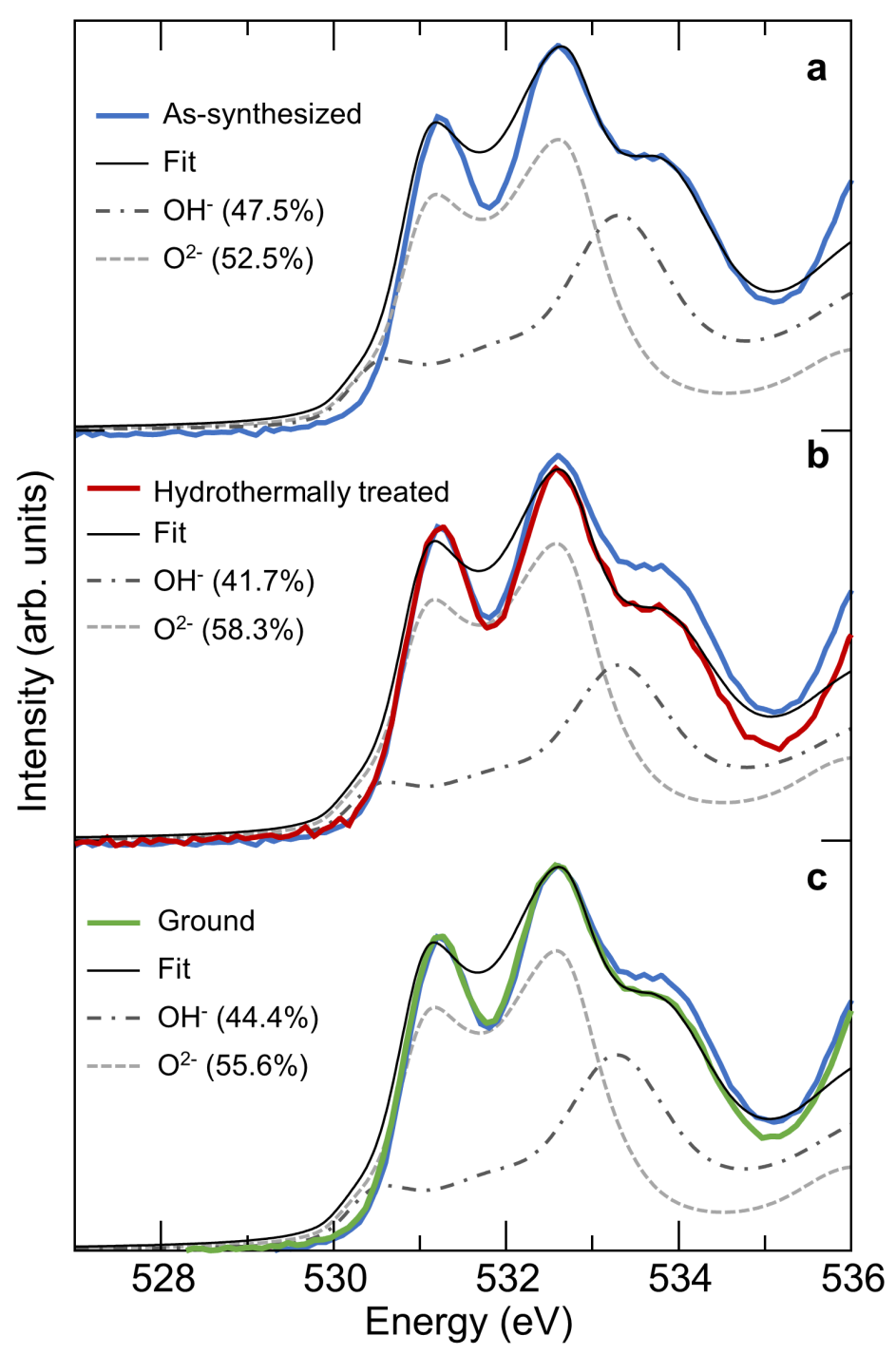

512

Figure 6. O K-edge XAS of goethite after sequential hydrothermal/grinding treatments.

513

514

515 


\section{REFERENCES}

1. Stumm, W.; Sulzberger, B., The cycling of iron in natural environments: Considerations based on laboratory studies of heterogeneous redox processes. Geochimica et Cosmochimica Acta 1992, $56,(8), 3233-3257$.

2. Jickells, T., Atmospheric inputs of metals and nutrients to the oceans: their magnitude and effects. Marine Chemistry 1995, 48, 199-214.

3. Williams, A. G. B.; Scherer, M. M., Spectroscopic Evidence for Fe(II)-Fe(III) Electron Transfer at the Iron Oxide-Water Interface. Environmental Science \& Technology 2004, 38, (18), 4782-4790.

4. Silvester, E.; Charlet, L.; Tournassat, C.; Géhin, A.; Grenèche, J.-M.; Liger, E., Redox potential measurements and Mössbauer spectrometry of $\mathrm{Fe}^{\mathrm{II}}$ adsorbed onto $\mathrm{Fe}^{\mathrm{III}}$ (oxyhydr)oxides. Geochimica et Cosmochimica Acta 2005, 69, (20), 4801-4815.

5. Larese-Casanova, P.; Scherer, M. M., Fe(II) Sorption on Hematite: New Insights Based on Spectroscopic Measurements. Environmental Science \& Technology 2007, 41, (2), 471-477.

6. Cwiertny, D. M.; Handler, R. M.; Schaefer, M. V.; Grassian, V. H.; Scherer, M. M., Interpreting nanoscale size-effects in aggregated Fe-oxide suspensions: Reaction of $\mathrm{Fe}(\mathrm{II})$ with Goethite. Geochimica et Cosmochimica Acta 2008, 72, (5), 1365-1380.

7. Yanina, S. V.; Rosso, K. M., Linked Reactivity at Mineral-Water Interfaces Through Bulk Crystal Conduction. Science 2008, 320, (5873), 218-222.

8. Amstaetter, K.; Borch, T.; Larese-Casanova, P.; Kappler, A., Redox Transformation of Arsenic by $\mathrm{Fe}(\mathrm{II})$-Activated Goethite $(\alpha-\mathrm{FeOOH})$. Environmental Science \& Technology 2010, 44, (1), 102-108.

9. Rosso, K. M.; Yanina, S. V.; Gorski, C. A.; Larese-Casanova, P.; Scherer, M. M., Connecting Observations of Hematite ( $\alpha$-Fe2O3) Growth Catalyzed by Fe(II). Environmental Science \& Technology 2010, 44, (1), 61-67.

10. Latta, D. E.; Bachman, J. E.; Scherer, M. M., Fe Electron Transfer and Atom Exchange in Goethite: Influence of Al-Substitution and Anion Sorption. Environmental Science \& Technology 2012, 46, (19), 10614-10623.

11. Neumann, A.; Olson, T. L.; Scherer, M. M., Spectroscopic Evidence for Fe(II)-Fe(III) Electron Transfer at Clay Mineral Edge and Basal Sites. Environmental Science \& Technology 2013, 47, (13), 6969-6977.

12. Pasakarnis, T.; McCormick, M. L.; Parkin, G. F.; Thompson, A.; Scherer, M. M., Fe"llaq$\mathrm{Fe}^{\mathrm{III}}$ oxide electron transfer and $\mathrm{Fe}$ exchange: effect of organic carbon. Environmental Chemistry 2015, 12, (1), 52-63.

13. Latta, D. E.; Neumann, A.; Premaratne, W. A. P. J.; Scherer, M. M., Fe(II)-Fe(III) Electron Transfer in a Clay Mineral with Low Fe Content. ACS Earth and Space Chemistry 2017, 1, (4), 197-208.

14. Gorski, C. A.; Scherer, M. M., Influence of Magnetite Stoichiometry on Fe $\mathrm{e}^{\mathrm{II}}$ Uptake and Nitrobenzene Reduction. Environmental Science \& Technology 2009, 43, (10), 3675-3680.

15. Schaefer, M. V.; Gorski, C. A.; Scherer, M. M., Spectroscopic Evidence for Interfacial $\mathrm{Fe}(\mathrm{II})-\mathrm{Fe}(\mathrm{III})$ Electron Transfer in a Clay Mineral. Environmental Science \& Technology 2011, $45,(2), 540-545$.

16. Handler, R. M.; Beard, B. L.; Johnson, C. M.; Scherer, M. M., Atom Exchange between Aqueous Fe(II) and Goethite: An Fe Isotope Tracer Study. Environmental Science \& Technology 2009, 43, (4), 1102-1107. 
17. Handler, R. M.; Frierdich, A. J.; Johnson, C. M.; Rosso, K. M.; Beard, B. L.; Wang, C.; Latta, D. E.; Neumann, A.; Pasakarnis, T.; Premaratne, W. A. P. J.; Scherer, M. M., Fe(II)-Catalyzed Recrystallization of Goethite Revisited. Environmental Science \& Technology 2014, 48, (19), $11302-11311$.

18. Latta, Drew E.; Gorski, Christopher A.; Scherer, Michelle M., Influence of $\mathrm{Fe}^{2+}$-catalysed iron oxide recrystallization on metal cycling. Biochemical Society Transactions 2012, 40, (6), 567 1191-1197.

19. Gorski, C. A.; Fantle, M. S., Stable mineral recrystallization in low temperature aqueous systems: A critical review. Geochimica et Cosmochimica Acta 2017, 198, 439-465. 20. Joshi, P.; Fantle, M. S.; Larese-Casanova, P.; Gorski, C. A., Susceptibility of Goethite to Fe ${ }^{2+}-$ Catalyzed Recrystallization over Time. Environmental Science \& Technology 2017. 21. Joshi, P.; Gorski, C. A., Anisotropic Morphological Changes in Goethite during $\mathrm{Fe}^{2+}$ Catalyzed Recrystallization. Environmental Science \& Technology 2016, 50, (14), 7315-7324.

22. Neumann, A.; Wu, L.; Li, W.; Beard, B. L.; Johnson, C. M.; Rosso, K. M.; Frierdich, A. J.; Scherer, M. M., Atom Exchange between Aqueous Fe(II) and Structural Fe in Clay Minerals. Environmental Science \& Technology 2015, 49, (5), 2786-2795.

23. Gorski, C. A.; Handler, R. M.; Beard, B. L.; Pasakarnis, T.; Johnson, C. M.; Scherer, M. M., Fe Atom Exchange between Aqueous $\mathrm{Fe}^{2+}$ and Magnetite. Environmental Science \& Technology 2012, 46, (22), 12399-12407.

580 24. Murray, G. C.; Hesterberg, D., Iron and phosphate dissolution during abiotic reduction of ferrihydrite-boehmite mixtures. Soil Sci. Soc. Am. J. 2006, 70, (4), 1318-1327.

25. Matocha, C. J.; Dhakal, P.; Pyzola, S. M., Chapter Four - The Role of Abiotic and Coupled Biotic/Abiotic Mineral Controlled Redox Processes in Nitrate Reduction. In Advances in Agronomy, Donald, L. S., Ed. Academic Press: 2012; Vol. Volume 115, pp 181-214.

26. Van Cleemput, O., Subsoils: chemo-and biological denitrification, $\mathrm{N}_{2} \mathrm{O}$ and $\mathrm{N}_{2}$ emissions. Nutrient Cycling in Agroecosystems 1998, 52, (2-3), 187-194.

27. Ernstsen, V., Reduction of Nitrate by $\mathrm{Fe}^{2+}$ in Clay Minerals. Clays and Clay Minerals 1996, 44, (5), 599-608.

28. Colombo, C.; Palumbo, G.; He, J.-Z.; Pinton, R.; Cesco, S., Review on iron availability in soil: interaction of Fe minerals, plants, and microbes. Journal of Soils and Sediments 2014, 14, (3), 538-548.

29. Weber, K. A.; Achenbach, L. A.; Coates, J. D., Microorganisms pumping iron: anaerobic microbial iron oxidation and reduction. Nat Rev Micro 2006, 4, (10), 752-764.

30. Chun, C. L.; Hozalski, R. M.; Arnold, W. A., Degradation of Drinking Water Disinfection Byproducts by Synthetic Goethite and Magnetite. Environmental Science \& Technology 2005, 39, (21), 8525-8532.

31. Peretyazhko, T.; Zachara, J. M.; Heald, S. M.; Jeon, B. H.; Kukkadapu, R. K.; Liu, C.; Moore, D.; Resch, C. T., Heterogeneous reduction of Tc(VII) by Fe(II) at the solid-water interface. Geochimica et Cosmochimica Acta 2008, 72, (6), 1521-1539.

32. Latta, D. E.; Boyanov, M. I.; Kemner, K. M.; O’Loughlin, E. J.; Scherer, M. M., Abiotic reduction of uranium by Fe (II) in soil. Applied geochemistry 2012, 27, (8), 1512-1524.

604 Science: Nano 2014, 1, (5), 478-487. 
34. Tomaszewski, E. J.; Lee, S.; Rudolph, J.; Xu, H.; Ginder-Vogel, M., The reactivity of Fe(II) associated with goethite formed during short redox cycles toward $\mathrm{Cr}(\mathrm{VI})$ reduction under oxic conditions. Chemical Geology 2017, 464, 101-109.

35. Frierdich, A. J.; Catalano, J. G., Fe(II)-Mediated Reduction and Repartitioning of Structurally Incorporated $\mathrm{Cu}, \mathrm{Co}$, and $\mathrm{Mn}$ in Iron Oxides. Environmental Science \& Technology 2012, 46, (20), 11070-11077.

36. Pedersen, H. D.; Postma, D.; Jakobsen, R.; Larsen, O., Fast transformation of iron oxyhydroxides by the catalytic action of aqueous Fe(II). Geochimica et Cosmochimica Acta 2005, 69, (16), 3967-3977.

37. Johnson, C. M.; Beard, B. L.; Roden, E. E., The Iron Isotope Fingerprints of Redox and Biogeochemical Cycling in Modern and Ancient Earth. Annual Review of Earth and Planetary Sciences 2008, 36, (1), 457-493.

38. Alexandrov, V.; Rosso, K. M., Ab initio modeling of Fe(II) adsorption and interfacial electron transfer at goethite $(\alpha-\mathrm{FeOOH})$ surfaces. Physical Chemistry Chemical Physics 2015, 17, (22), 14518-14531.

39. Kubicki, J. D.; Tunega, D.; Kraemer, S., A density functional theory investigation of oxalate and $\mathrm{Fe}(\mathrm{II})$ adsorption onto the (010) goethite surface with implications for ligand- and reductionpromoted dissolution. Chemical Geology 2016.

40. Russell, B.; Payne, M.; Ciacchi, L. C., Density functional theory study of Fe(II) adsorption and oxidation on goethite surfaces. Physical Review B 2009, 79, (16), 165101.

41. Zarzycki, P.; Kerisit, S.; Rosso, K. M., Molecular Dynamics Study of Fe(II) Adsorption, Electron Exchange, and Mobility at Goethite $(\alpha-\mathrm{FeOOH})$ Surfaces. The Journal of Physical Chemistry C 2015, 119, (6), 3111-3123.

42. Soltis, J. A.; Schwartzberg, A. M.; Zarzycki, P.; Penn, R. L.; Rosso, K. M.; Gilbert, B., Electron Mobility and Trapping in Ferrihydrite Nanoparticles. ACS Earth and Space Chemistry 2017, 1, (4), 216-226.

43. Schwertmann, U.; Cambier, P.; Murad, E., Properties of goethites of varying crystallinity. Clays and Clay minerals 1985, 33, (5), 369-378.

44. Strauss, R.; Brümmer, G. W.; Barrow, N. J., Effects of crystallinity of goethite: I. Preparation and properties of goethites of differing crystallinity. European Journal of Soil Science 1997, 48, (1), 87-99.

45. Madsen, D. E.; Cervera-Gontard, L.; Kasama, T.; Dunin-Borkowski, R. E.; Koch, C. B.; Hansen, M. F.; Frandsen, C.; Mørup, S., Magnetic fluctuations in nanosized goethite $(\alpha-\mathrm{FeOOH})$ grains. Journal of Physics: Condensed Matter 2009, 21, (1), 016007.

46. Barrero, C. A.; Betancur, J. D.; Greneche, J. M.; Goya, G. F.; Berquó, T. S., Magnetism in non-stoichiometric goethite of varying total water content and surface area. Geophysical Journal International 2006, 164, (2), 331-339.

47. Bocquet, S.; Hill, A., Correlation of Néel temperature and vacancy defects in fine-particle goethites. Physics and Chemistry of Minerals 1995, 22, (8), 524-528.

48. Cornell, R. M.; Schwertmann, U., Crystal Structure. In The Iron Oxides, Wiley-VCH Verlag GmbH \& Co. KGaA: 2004; pp 9-38.

49. De Yoreo, J. J.; Gilbert, P. U.; Sommerdijk, N. A.; Penn, R. L.; Whitelam, S.; Joester, D.; Zhang, H.; Rimer, J. D.; Navrotsky, A.; Banfield, J. F., Crystallization by particle attachment in synthetic, biogenic, and geologic environments. Science 2015, 349, (6247), aaa6760.

50. Penn, R. L.; Banfield, J. F., Imperfect Oriented Attachment: Dislocation Generation in DefectFree Nanocrystals. Science 1998, 281, (5379), 969-971. 
51. Banfield, J. F.; Welch, S. A.; Zhang, H.; Ebert, T. T.; Penn, R. L., Aggregation-Based Crystal Growth and Microstructure Development in Natural Iron Oxyhydroxide Biomineralization Products. Science 2000, 289, (5480), 751-754. 52. Brož, D.; Sedlák, B., Surface ferrimagnetism of synthetic goethite. Journal of Magnetism and Magnetic Materials 1991, 102, (1), 103-108.

53. Bocquet, S.; Pollard, R. J.; Cashion, J. D., Dynamic magnetic phenomena in fine-particle goethite. Physical Review B 1992, 46, (18), 11657-11664. 54. Stacey, F. D.; Banerjee, S. K., Chapter 2 - Magnetic Minerals. In Developments in Solid Earth Geophysics, Frank D, S.; Subir K, B., Eds. Elsevier: 1974; Vol. Volume 5, pp 25-40.

660 55. Özdemir, Ö.; Dunlop, D. J., Thermoremanence and Néel temperature of goethite. Geophysical 661 Research Letters 1996, 23, (9), 921-924.

662 56. Fischer, L.; Mühlen, E. Z.; Brümmer, G. W.; Niehus, H., Atomic force microscopy (AFM) 663 investigations of the surface topography of a multidomain porous goethite. European Journal of 664 Soil Science 1996, 47, (3), 329-334.

665 57. Schwertmann, U.; Cornell, R. M., Goethite. In Iron Oxides in the Laboratory, Wiley-VCH 666 Verlag GmbH: 2007; pp 67-92.

667 58. Good, N. E.; Winget, G. D.; Winter, W.; Connolly, T. N.; Izawa, S.; Singh, R. M. M., Hydrogen Ion Buffers for Biological Research*. Biochemistry 1966, 5, (2), 467-477.

59. Tamura, H.; Goto, K.; Yotsuyanagi, T.; Nagayama, M., Spectrophotometric determination of iron(II) with 1,10-phenanthroline in the presence of large amounts of iron(III). Talanta 1974, 21, (4), 314-318.

60. Rancourt, D. G.; Ping, J. Y., Voigt-based methods for arbitrary-shape static hyperfine parameter distributions in Mössbauer spectroscopy. Nuclear Instruments and Methods in Physics Research Section B: Beam Interactions with Materials and Atoms 1991, 58, (1), 85-97.

61. Joly, Y., X-ray absorption near-edge structure calculations beyond the muffin-tin approximation. Physical Review B 2001, 63, (12), 125120.

62. Hedin, L.; Lundqvist, B. I., Explicit local exchange-correlation potentials. Journal of Physics C: Solid State Physics 1971, 4, (14), 2064.

63. Piepenbrock, A.; Schröder, C.; Kappler, A., Electron transfer from humic substances to biogenic and abiogenic Fe (III) oxyhydroxide minerals. Environmental science \& technology 2014, 48, (3), 1656-1664.

64. Buchholz, A.; Laskov, C.; Haderlein, S. B., Effects of Zwitterionic Buffers on Sorption of Ferrous Iron at Goethite and Its Oxidation by CCl4. Environmental Science \& Technology 2011, 45, (8), 3355-3360.

65. Cornell, R. M.; Schwertmann, U., Formation. In The Iron Oxides, Wiley-VCH Verlag GmbH \& Co. KGaA: 2004; pp 345-364.

66. Burns, R. G., Intervalence transitions in mixed valence minerals of iron and titanium. Annual Review of Earth and Planetary Sciences 1981, 9, (1), 345-383.

67. Liu, J.; Pearce, C. I.; Liu, C.; Wang, Z.; Shi, L.; Arenholz, E.; Rosso, K. M., $\mathrm{Fe}_{3-\mathrm{x}} \mathrm{Ti}_{\mathrm{x}} \mathrm{O}_{4}$ Nanoparticles as Tunable Probes of Microbial Metal Oxidation. Journal of the American Chemical Society 2013, 135, (24), 8896-8907.

68. Sassi, M.; Pearce, C. I.; Bagus, P. S.; Arenholz, E.; Rosso, K. M., First Principles Fe L2,3Edge and O K-Edge XANES and XMCD Spectra for Iron Oxides. The Journal of Physical Chemistry A 2017.

69. Gilbert, B.; Erbs, J. J.; Penn, R. L.; Petkov, V.; Spagnoli, D.; Waychunas, G. A., A disordered nanoparticle model for 6-line ferrihydrite. American Mineralogist 2013, 98, (8-9), 1465-1476. 
70. Frierdich, A. J.; Catalano, J. G., Controls on Fe(II)-Activated Trace Element Release from

698 Goethite and Hematite. Environmental Science \& Technology 2012, 46, (3), 1519-1526.

699 71. Jones, A. M.; Collins, R. N.; Rose, J.; Waite, T. D., The effect of silica and natural organic

700 matter on the $\mathrm{Fe}(\mathrm{II})$-catalysed transformation and reactivity of $\mathrm{Fe}(\mathrm{III})$ minerals. Geochimica et

701 Cosmochimica Acta 2009, 73, (15), 4409-4422.

702 72. Frierdich, A. J.; Helgeson, M.; Liu, C.; Wang, C.; Rosso, K. M.; Scherer, M. M., Iron atom 703 exchange between hematite and aqueous Fe(II). Environmental science \& technology 2015, 49, 704 (14), 8479-8486.

705 73. Roden, E. E.; Urrutia, M. M.; Mann, C. J., Bacterial Reductive Dissolution of Crystalline 706 Fe(III) Oxide in Continuous-Flow Column Reactors. Applied and Environmental Microbiology 707 2000, 66, (3), 1062-1065.

708 74. Roden, E. E.; Urrutia, M. M., Influence of biogenic Fe (II) on bacterial crystalline Fe (III) 709 oxide reduction. Geomicrobiology journal 2002, 19, (2), 209-251.

710 75. Klausen, J.; Trober, S. P.; Haderlein, S. B.; Schwarzenbach, R. P., Reduction of substituted 711 nitrobenzenes by Fe(II) in aqueous mineral suspensions. Environmental Science and Technology 712 1995, 29, (9), 2396-2404.

713 76. Amonette, J. E.; Workman, D. J.; Kennedy, D. W.; Fruchter, J. S.; Gorby, Y. A., 714 Dechlorination of carbon tetrachloride by Fe(II) associated with goethite. Environmental Science 715 \& Technology 2000, 34, (21), 4606-4613.

716 77. Gorski, C. A.; Edwards, R.; Sander, M.; Hofstetter, T. B.; Stewart, S. M., Thermodynamic 717 Characterization of Iron Oxide-Aqueous $\mathrm{Fe}^{2+}$ Redox Couples. Environmental Science \& 718 Technology 2016, 50, (16), 8538-8547.

719 78. Fan, D.; Bradley, M. J.; Hinkle, A. W.; Johnson, R. L.; Tratnyek, P. G., Chemical Reactivity 720 Probes for Assessing Abiotic Natural Attenuation by Reducing Iron Minerals. Environmental 721 Science \& Technology 2016, 50, (4), 1868-1876.

722 79. Wang, L.; Giammar, D. E., Effects of $\mathrm{pH}$, dissolved oxygen, and aqueous ferrous iron on the 723 adsorption of arsenic to lepidocrocite. Journal of colloid and interface science 2015, 448, 331724338.

725 80. Ilgen, A. G.; Kruichak, J.; Artyushkova, K.; Newville, M.; Sun, C.-J., Redox transformations 726 of As and Se at the surfaces of natural and synthetic ferric nontronites: role of structural and 727 adsorbed Fe(II). Environmental Science \& Technology 2017. 


\section{Supporting Information}

\section{The Role of Defects in Fe(II)-Goethite Electron Transfer}

Luiza Notini', Drew E. Latta', Anke Neumann'², Carolyn I. Pearces, Michel Sassi', Alpha T. $\mathrm{N}^{\prime}$ Diaye $^{4}$, Kevin M. Rosso ${ }^{3}$, and Michelle Scherer ${ }^{1 *}$

'Department of Civil and Environmental Engineering, University of Iowa, Iowa City, IA, 52242, United States.

${ }^{2}$ School of Engineering, Newcastle University, Newcastle upon Tyne, NE1 7RU, United Kingdom.

Pacific Northwest National Laboratory, Richland, WA 99352, United States

${ }^{4}$ Advanced Light Source, Lawrence Berkeley National Laboratory, Berkeley, CA 94720

Figures: 12

Tables: 3

Pages: 22 


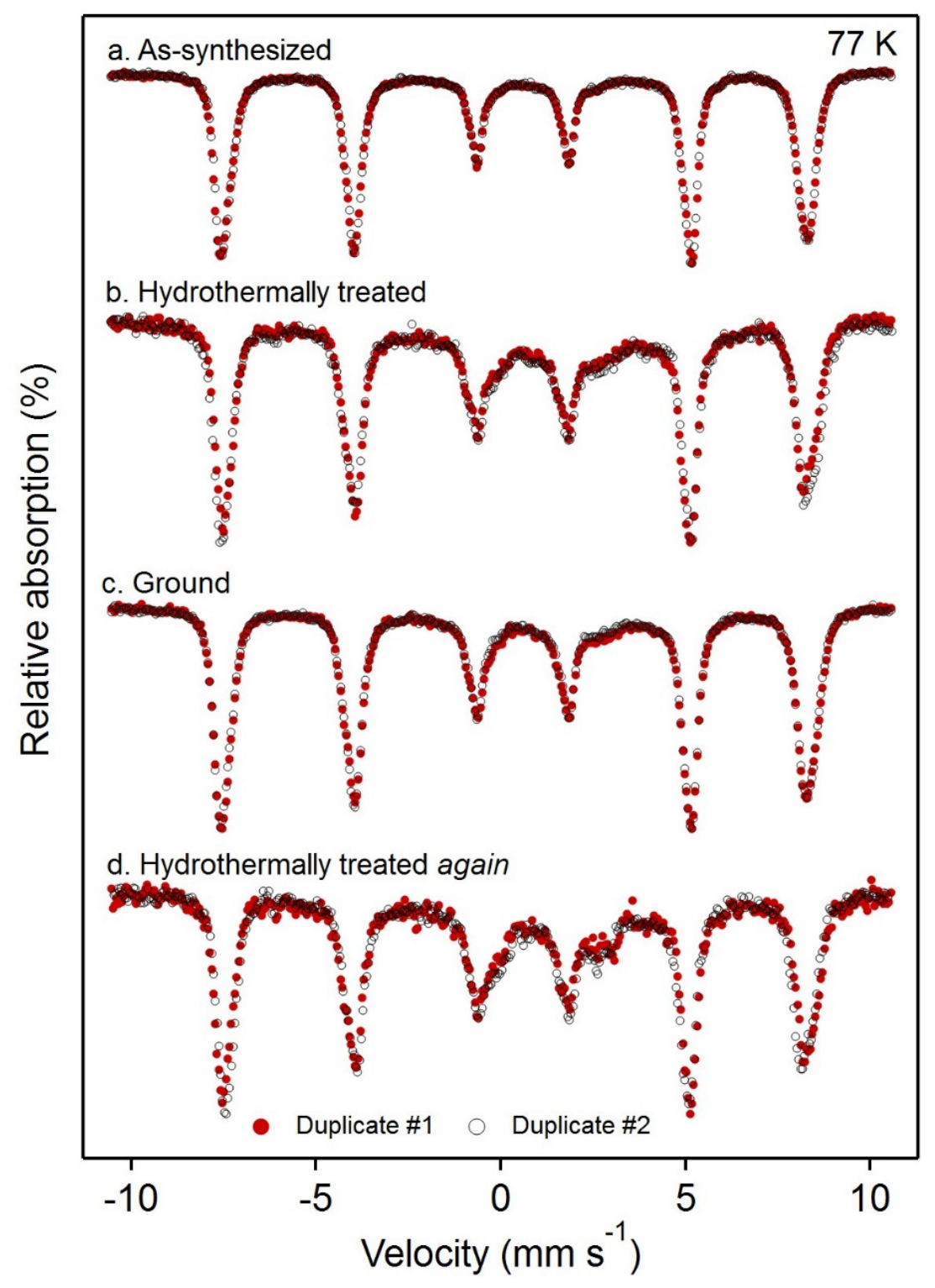

Figure S1. Mössbauer spectra of $1 \mathrm{mM}{ }^{57} \mathrm{Fe}(\mathrm{II})$ reacted with goethite after sequential hydrothermal/grinding treatments. Different colors represent different batches. 


\section{Fitting Mössbauer spectra}

We tried different approaches to fit the spectral area not captured by the two goethite sextets. In the first approach we used a doublet as in some of our and others' work. ${ }^{1,2}$ This fitting procedure, however, does not capture any area in the ranges of -4 to -1 and 4 to $5 \mathrm{~mm} \mathrm{~s}^{-1}$. In the second approach we added a doublet and a broad, partially order collapsed feature, as in our previous work (Figure S2). ${ }^{3}$ We qualitatively concluded based on visual inspection of multiple fits that the doublet along with collapsed sextet is the best approach. Our qualitative analysis is quantitatively supported by a smaller $\chi^{2}$ values calculated when the collapsed sextet was included.

To model the collapsed feature parameters, we attempted to fit the spectrum by inputting a wide range of center shifts (from 0.1 to $1.7 \mathrm{~mm} \mathrm{~s}^{-1}$ ). The parameters converged to two stable solutions, with center shifts of $\approx 0.65$ or $\approx 1.3 \mathrm{~mm} \mathrm{~s}^{-1}$. A center shift $\approx 1.3 \mathrm{~mm} \mathrm{~s}^{-1}$ would be an indication of an $\mathrm{Fe}(\mathrm{II})$ compound, however the presence of ferrous hydroxide can be ruled out by XRD (Figure S3) and based on our observation of a high hyperfine field of $25 \mathrm{~T}$, compared to absence of magnetic ordering for ferrous hydroxide at $77 \mathrm{~K}$ (doublet parameter: $\mathrm{CS}=1.21 \mathrm{~mm} \mathrm{~s}^{-}$ ${ }^{1}$; QS $\left.=2.95 \mathrm{~mm} \mathrm{~s}^{-1}\right) .{ }^{4}$ For that reason we chose to fit our spectra using the center shift of $0.65 \mathrm{~mm}$ $\mathrm{s}^{-1}$, as this value would be reasonable for a mixed Fe(II)-Fe(III) compound. ${ }^{5}$ We also collected Mössbauer data at $4 \mathrm{~K}$, which showed no indication of magnetic ordering, ruling out the presence well-defined mineral Fe(II)-Fe(III) compounds (e.g., green rust). More importantly though, neither the relative area of the components nor the remaining parameters of the sextets seem to be

substantially affected by the two different center shifts. Thereby, we limited our interpretation to suggest that the collapsed feature is a non-well defined Fe(II)-Fe(III) compound, and we used the fitting of the Mössbauer spectra to calculate the relative area of the component. 


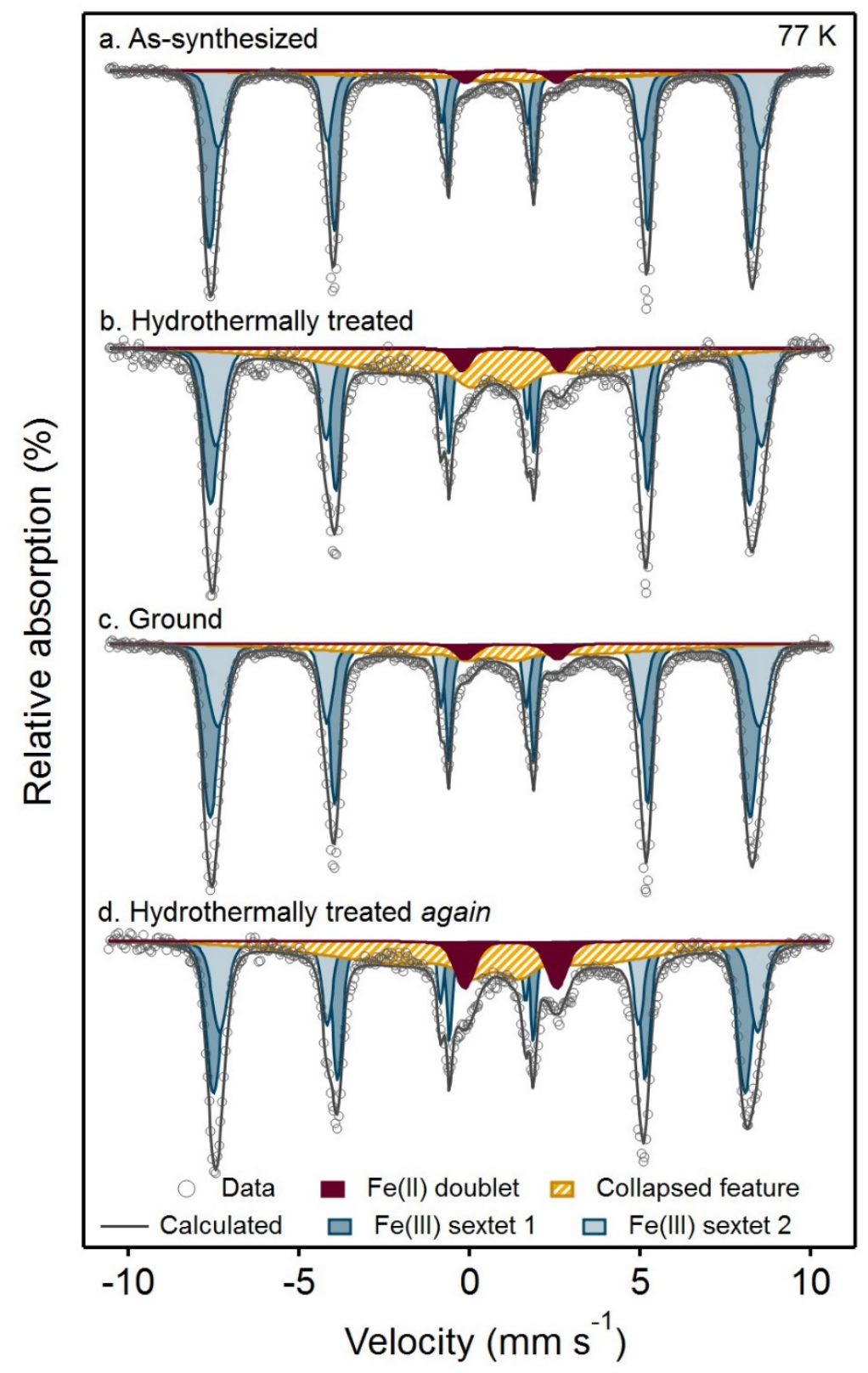

Figure S2. Mössbauer spectra of $1 \mathrm{mM}{ }^{\mathrm{s}} \mathrm{Fe}(\mathrm{II})$ reacted with goethite after sequential hydrothermal/grinding treatments. Experimental conditions: $\left[{ }^{56} \mathrm{Gt}\right]=2 \mathrm{~g} \mathrm{~L}^{-1} ; 1 \mathrm{mM} \mathrm{Fe}(\mathrm{II})$ in 25 $\mathrm{mM} \mathrm{KBr} / 25 \mathrm{mM}$ HEPES at $\mathrm{pH}$ 7.5. 


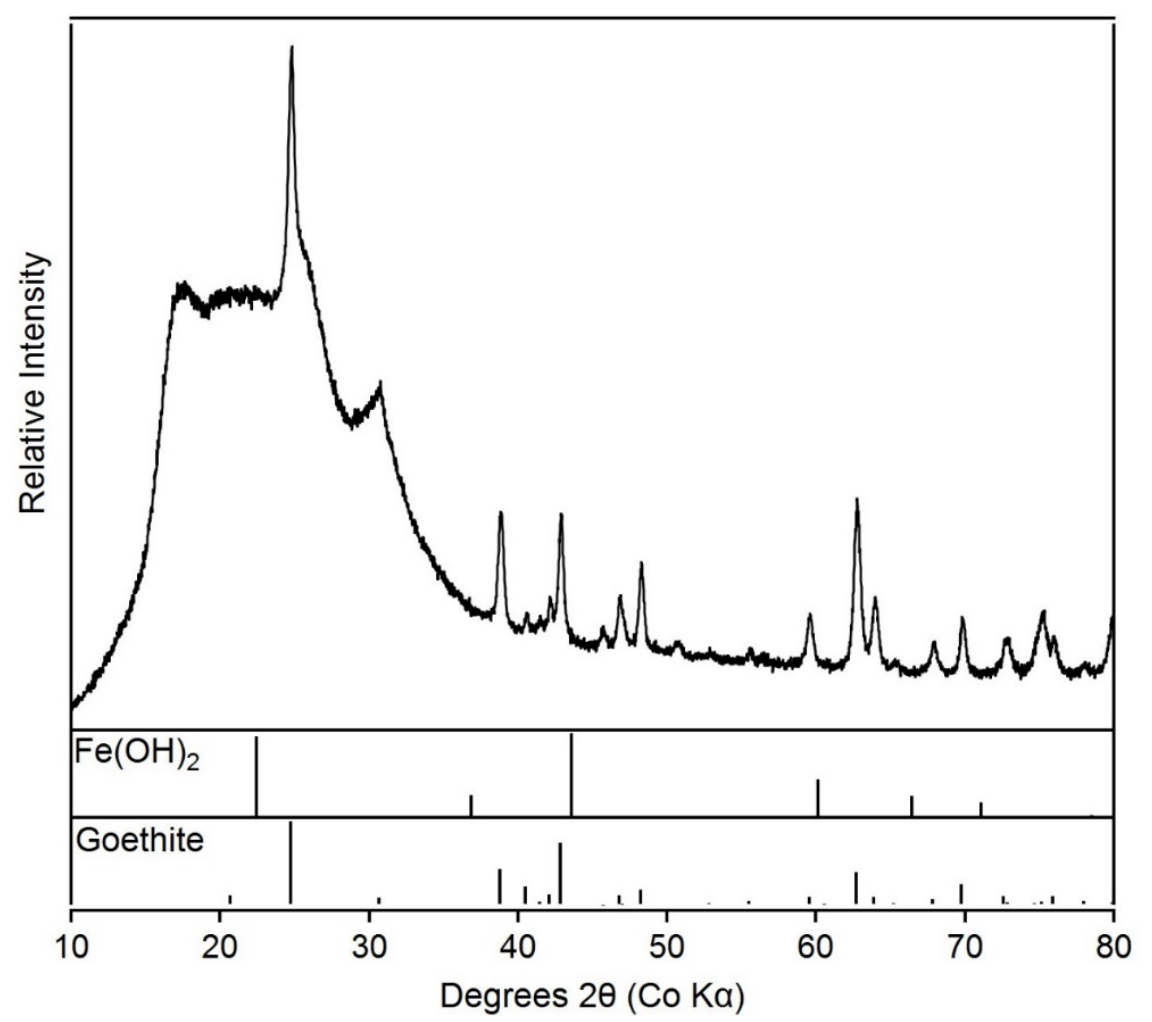

Figure S3. Power X-ray diffraction of ${ }^{56} \mathrm{Fe}$ as-synthesized goethite reacted with $1 \mathrm{mM}{ }^{57} \mathrm{Fe}(\mathrm{II})$. Sample was filtered and protected against oxidation with Kapton tape. 


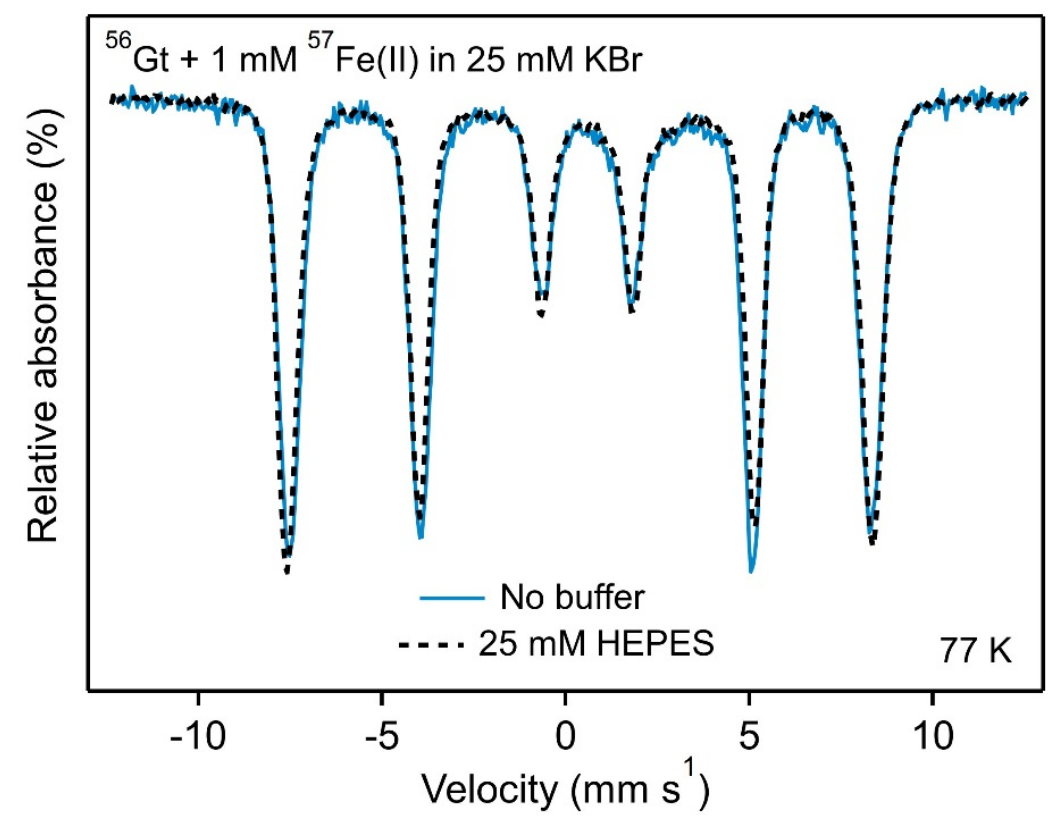

Figure S4. Mössbauer spectra of ${ }^{56}$ goethite reacted with $1 \mathrm{mM}{ }^{57} \mathrm{Fe}(\mathrm{II})$ in the presence and in the absence of $25 \mathrm{mM}$ HEPES. Experimental conditions: $\left[{ }^{56} \mathrm{Gt}\right]=2 \mathrm{~g} \mathrm{~L}-1 ; 25 \mathrm{mM} \mathrm{KBr}$; initial $\mathrm{pH}$ 7.5. 


\section{Mössbauer spectra of extracted and oxidized samples}

In order to determine what is removed from the reacted solids upon acid extractions or air oxidation, we compared the spectra of the $\mathrm{HCl}$ extracted goethite and oxidized goethite (Figure 2). The oxidation of the sample revealed the complete removal of the Fe(II) doublet and the collapsed feature and we hypothesize that this is due to the Fe(II) content on these features. The spectrum contains two sextets $\left(\mathrm{CS} \approx 0.48 \mathrm{~mm} \mathrm{~s}^{-1}, \mathrm{QS} \approx-0.16 \mathrm{~mm} \mathrm{~s}^{-1}\right.$ and $\mathrm{CS} \approx 0.5 \mathrm{~mm} \mathrm{~s}^{-1}, \mathrm{QS} \approx$ $0.08 \mathrm{~mm} \mathrm{~s}^{-1}$ ) as was observed after reaction of goethite with ${ }^{5} \mathrm{Fe}(\mathrm{II})$ (Table S1). To rule out aging as a factor in removing the doublet and collapsed feature we left one sample inside the glovebox where it was not exposed to oxygen and the collapsed feature and Fe(II) remained (data not shown).

In contrast, the $\mathrm{HCl}$-extracted goethite spectrum clearly has a third $\mathrm{Fe}(\mathrm{III})$ sextet. The Mössbauer parameters of the third Fe(III) sextet (Table S1) are similar to those reported for akaganéite $(\beta-\mathrm{FeOOH}),{ }^{6}$ and we hypothesize akaganéite was formed due to the extractant's chloride content and low $\mathrm{pH}$ value.

To confirm that the formation of akaganéite was due to the acid extraction, we then tried a mild sequential extraction with buffer ( $\mathrm{pH} 7.5,1$ hour) followed by $1 \mathrm{M} \mathrm{CaCl}_{2}$ (pH 7, 4 hours) and $1 \mathrm{M} \mathrm{NaH}_{2} \mathrm{PO}_{4}$ (pH 5, 18 hours). A 30 min wash step with DI water was carried out after the $\mathrm{CaCl}_{2}$ and $\mathrm{NaH}_{2} \mathrm{PO}_{4}$. The Mössbauer spectrum of the extracted solids (Figure S5) showed removal of most of the collapsed feature (Table S1), and $80 \%$ of sorbed Fe(II) was recovered during the sequential extractions (Table S2). In contrast to the spectrum of the $\mathrm{HCl}$-extracted goethite, the Mössbauer spectrum of the sequentially extracted solids did not contain a third sextet. The appearance of the third sextet after the $\mathrm{HCl}$ extraction and its absence after the sequential extraction further suggests the component is a result of the acidic $\mathrm{pH}$ value and the high chloride content of the extraction solution, and did not result from the removal of $\mathrm{Fe}(\mathrm{II})$.

Taken together the extraction and oxidation treatments confirm that removal of Fe(II) is concomitant with the loss of the collapsed feature, and provides a line of evidence that the collapsed feature, at least in part, arises from the presence of Fe(II) in the solids formed during the electron transfer from $\mathrm{Fe}(\mathrm{II})$ to goethite. 


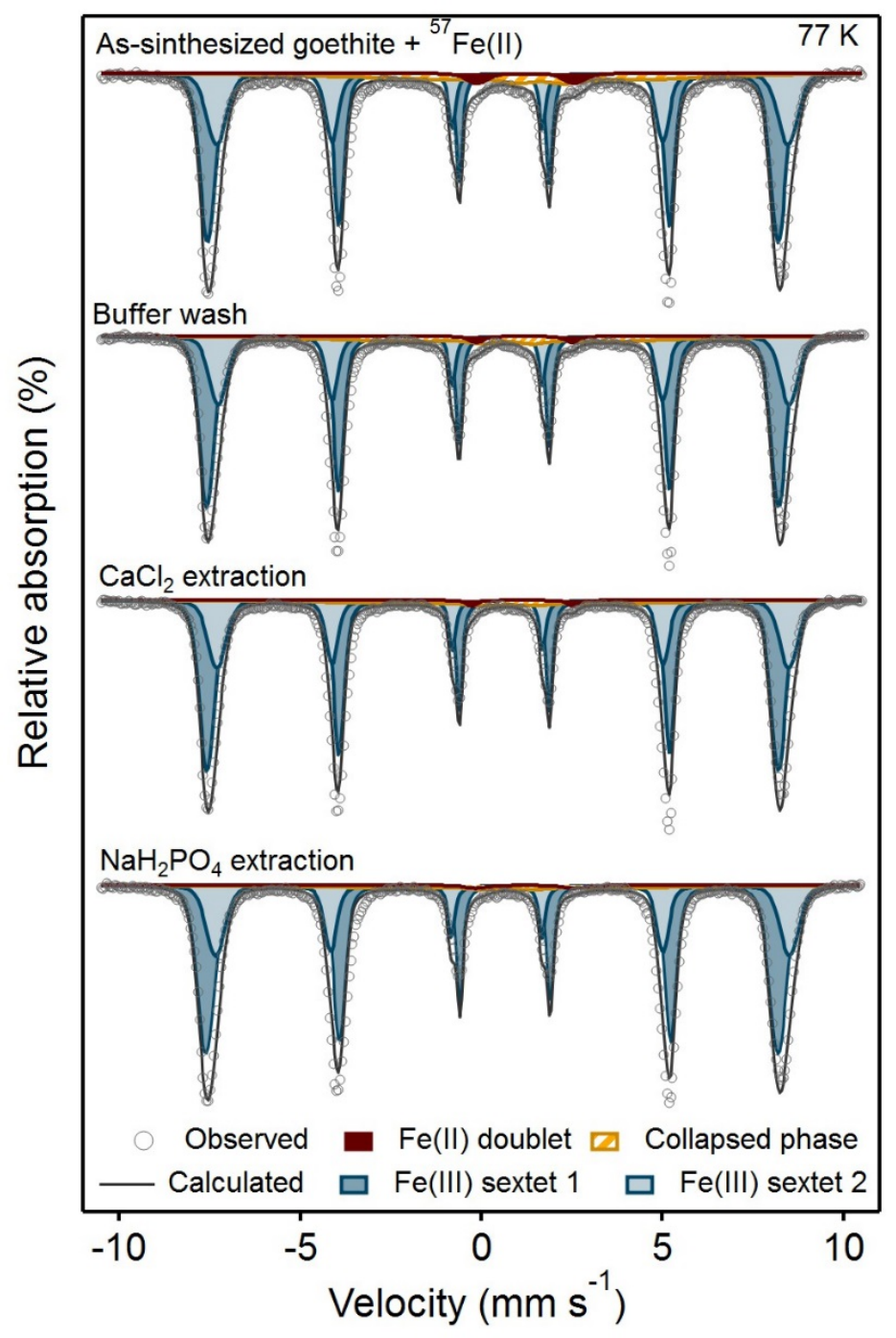

Figure S5. Mössbauer spectra of ${ }^{s} \mathrm{Fe}$ as-synthesized goethite reacted with $1 \mathrm{mM}{ }^{s} \mathrm{Fe}(\mathrm{II})$, before and after sequential buffer wash and $1 \mathrm{M} \mathrm{CaCl}_{2}$ and $\mathrm{NaH}_{2} \mathrm{PO}_{4}$ extraction. 


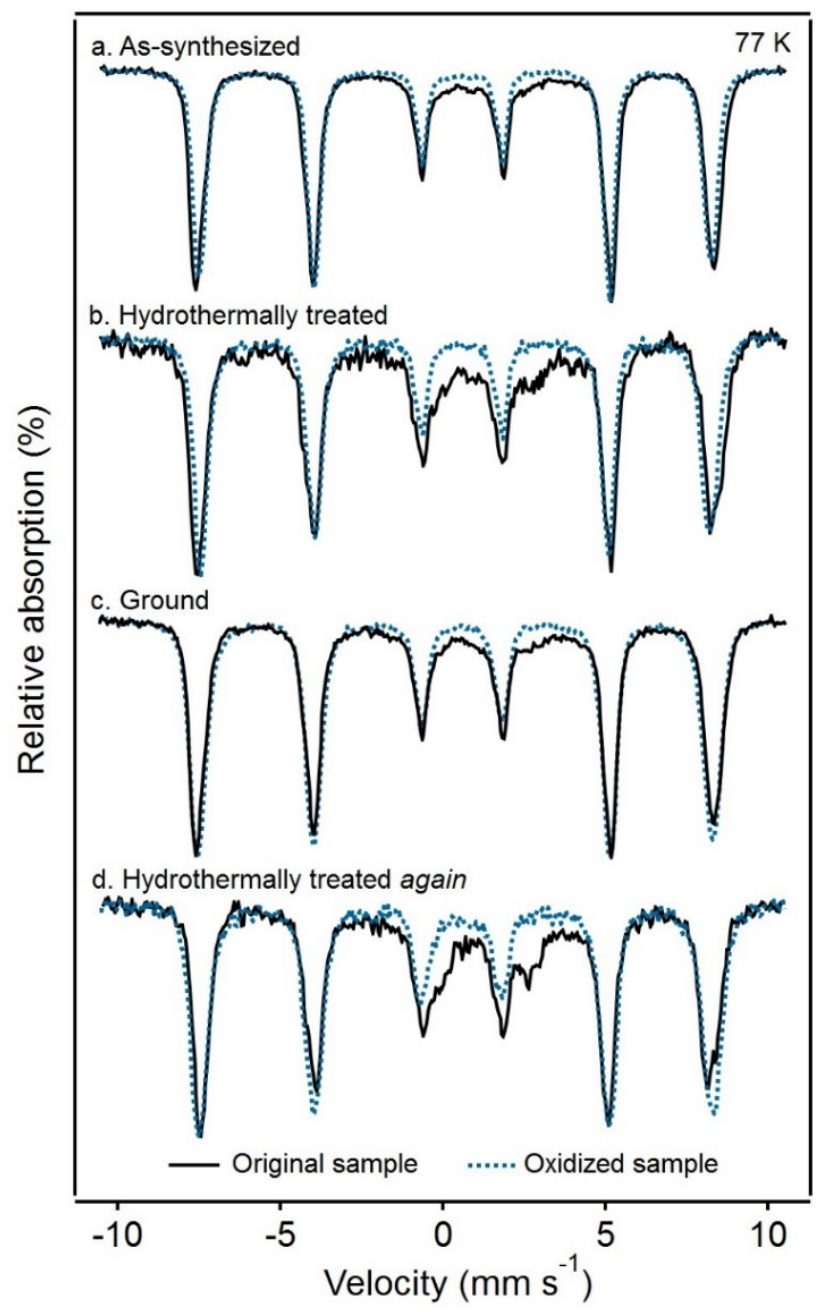

Figure S6. Mössbauer spectra of $1 \mathrm{mM}{ }^{57} \mathrm{Fe}(\mathrm{II})$ reacted with goethite after sequential hydrothermal/grinding treatments, before (original: solid lines) and after oxidation (oxidized: dotted lines). 


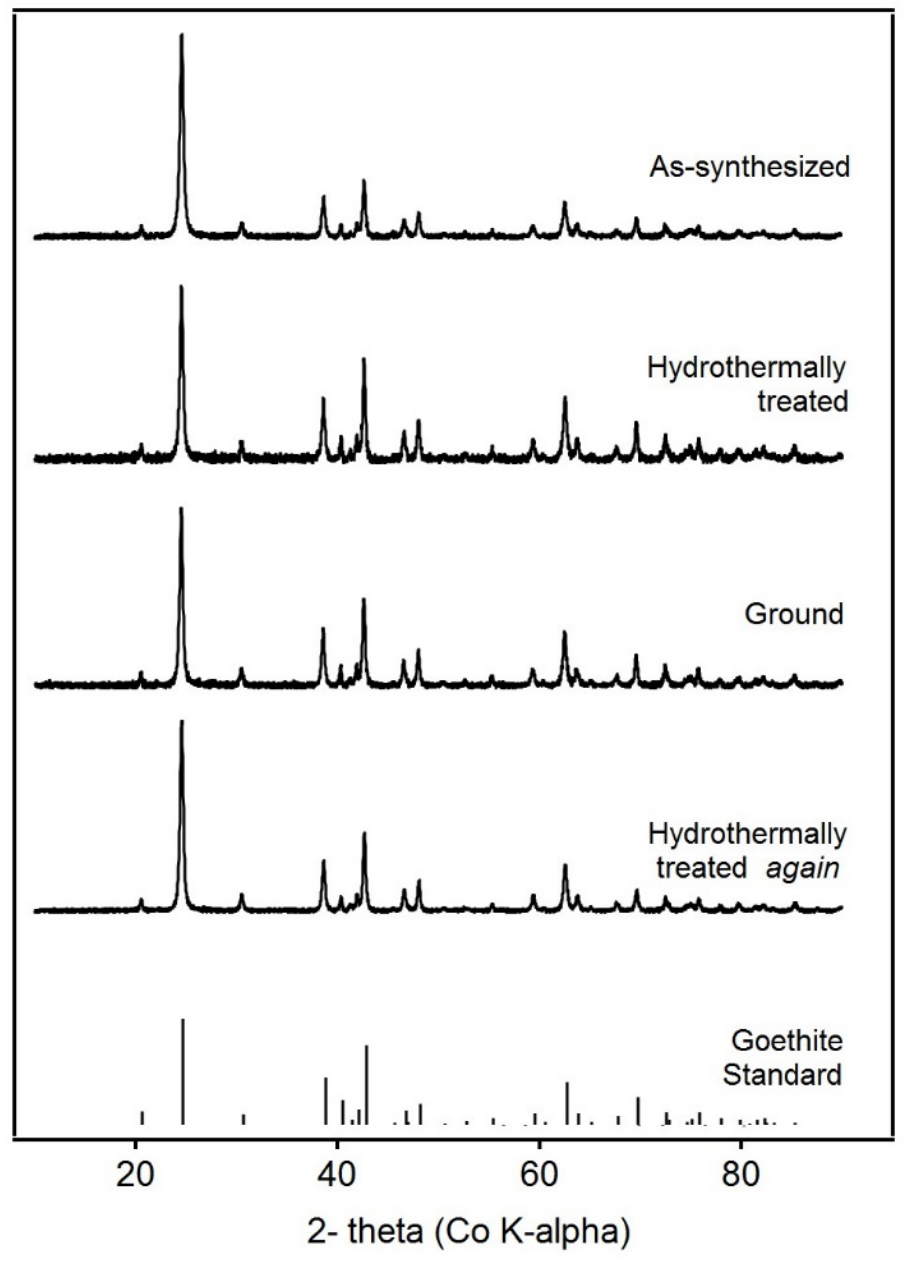

Figure S7. XRD of goethite after sequential hydrothermal/grinding treatments. 


\section{As-synthesized goethite}
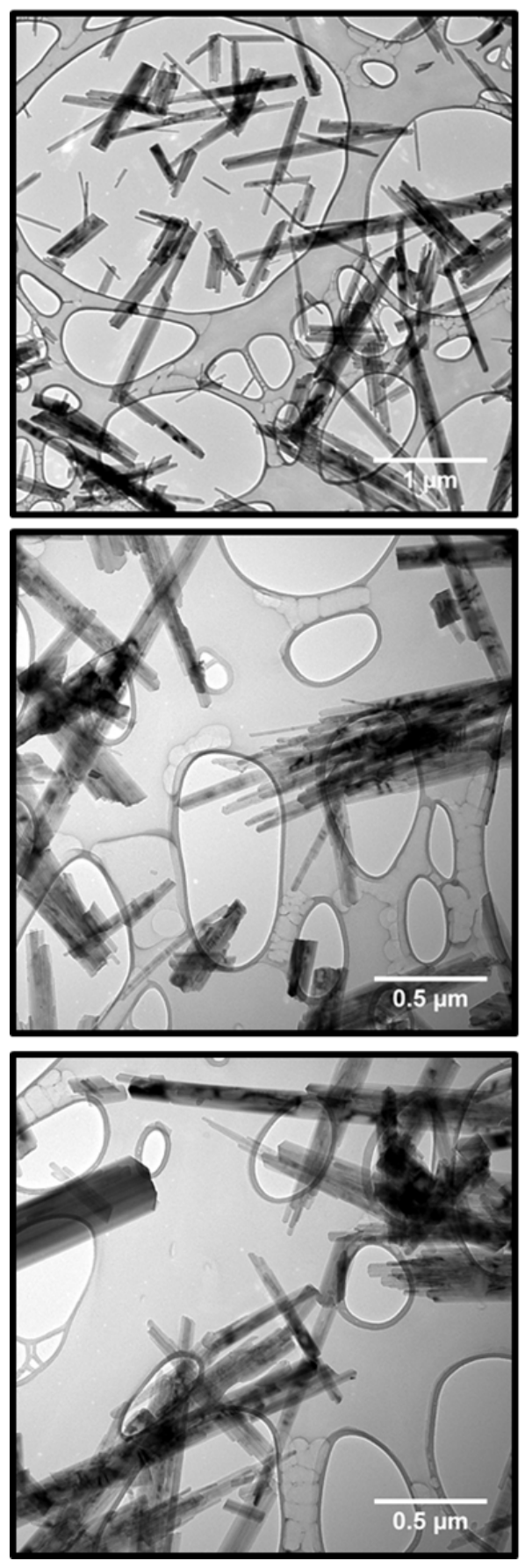

Hydrothermally treated goethite
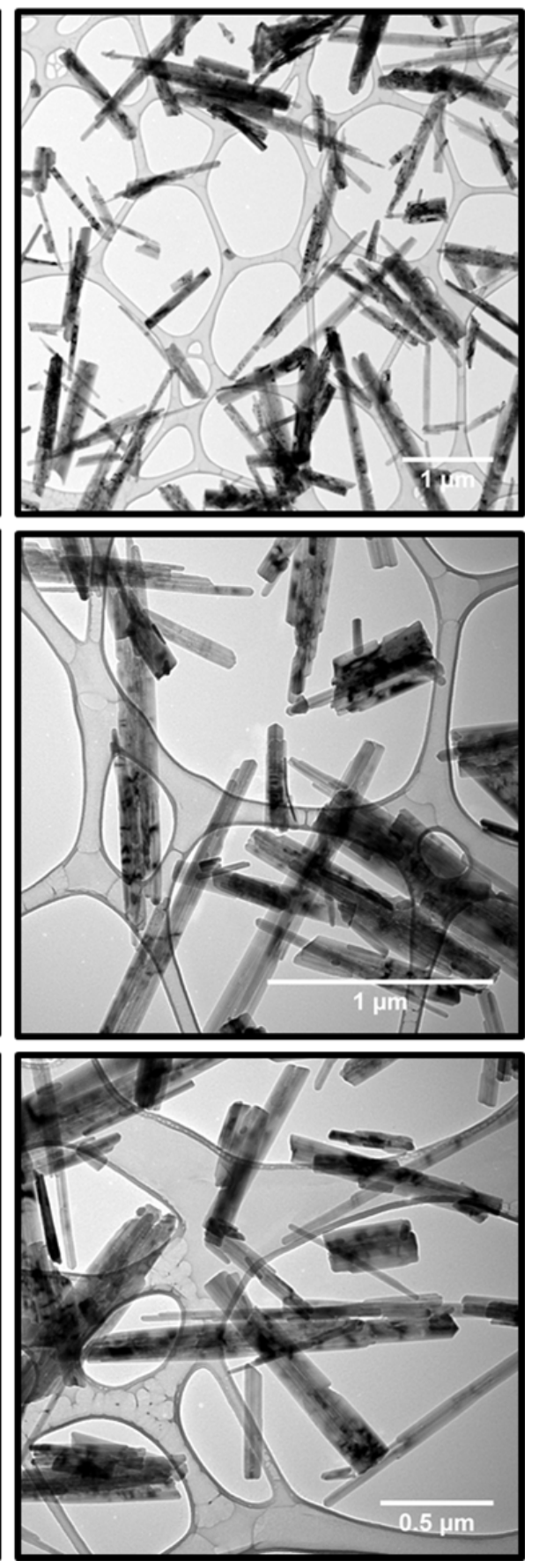

Figure S8. TEM picture of as-synthesized goethite and hydrothermally treated goethite. 

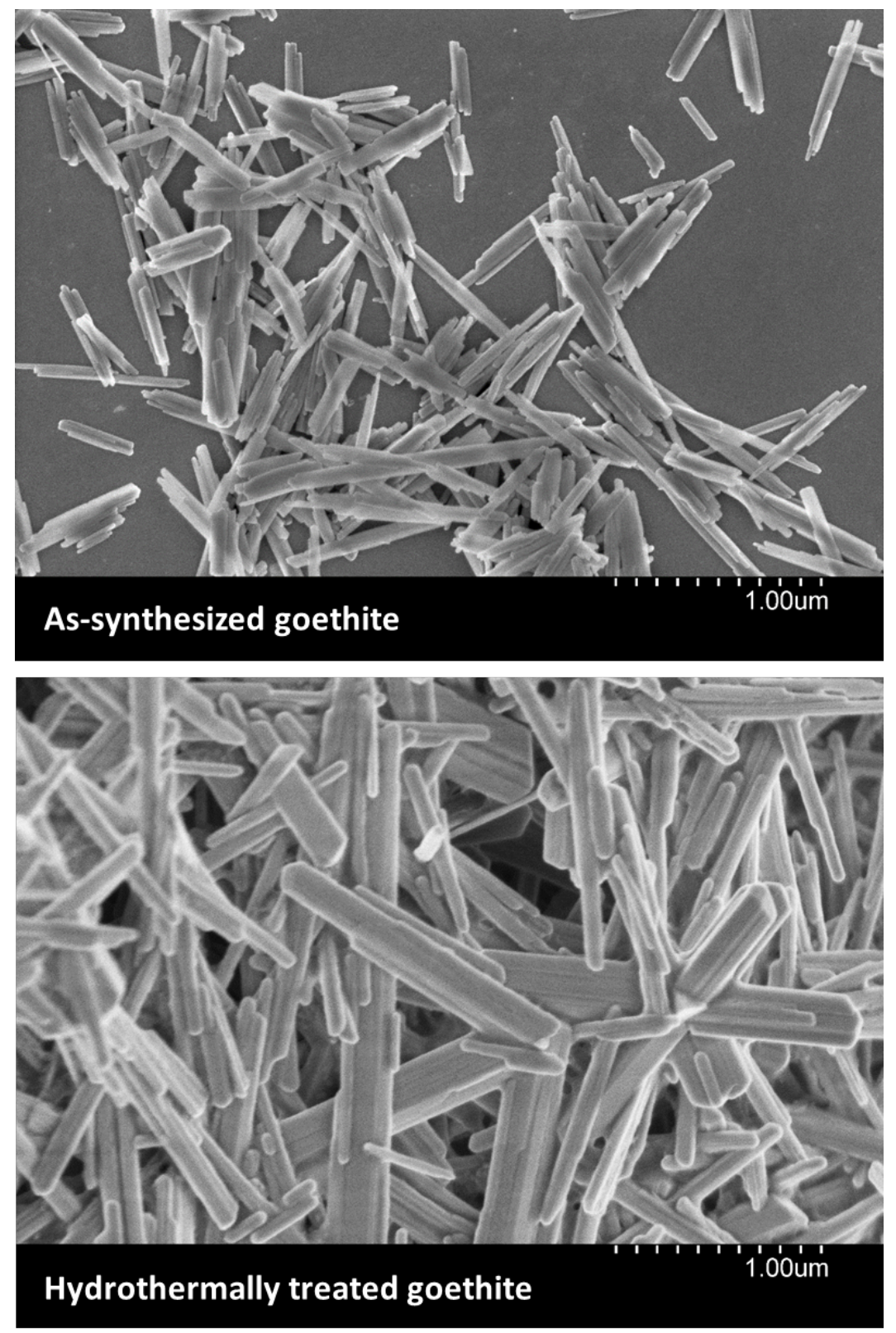

Figure S9. SEM picture of as-synthesized goethite and hydrothermally treated goethite. 


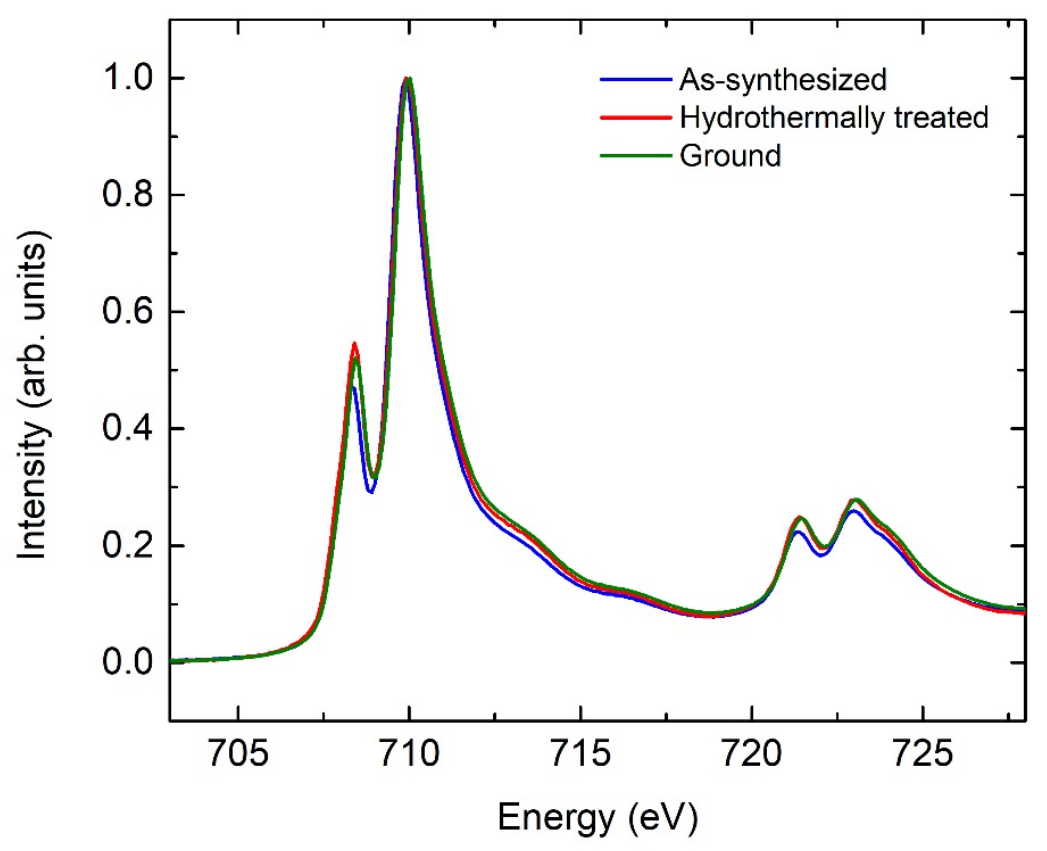

Figure S10. Fe L-edge XAS of goethite after sequential hydrothermal/grinding treatments. 


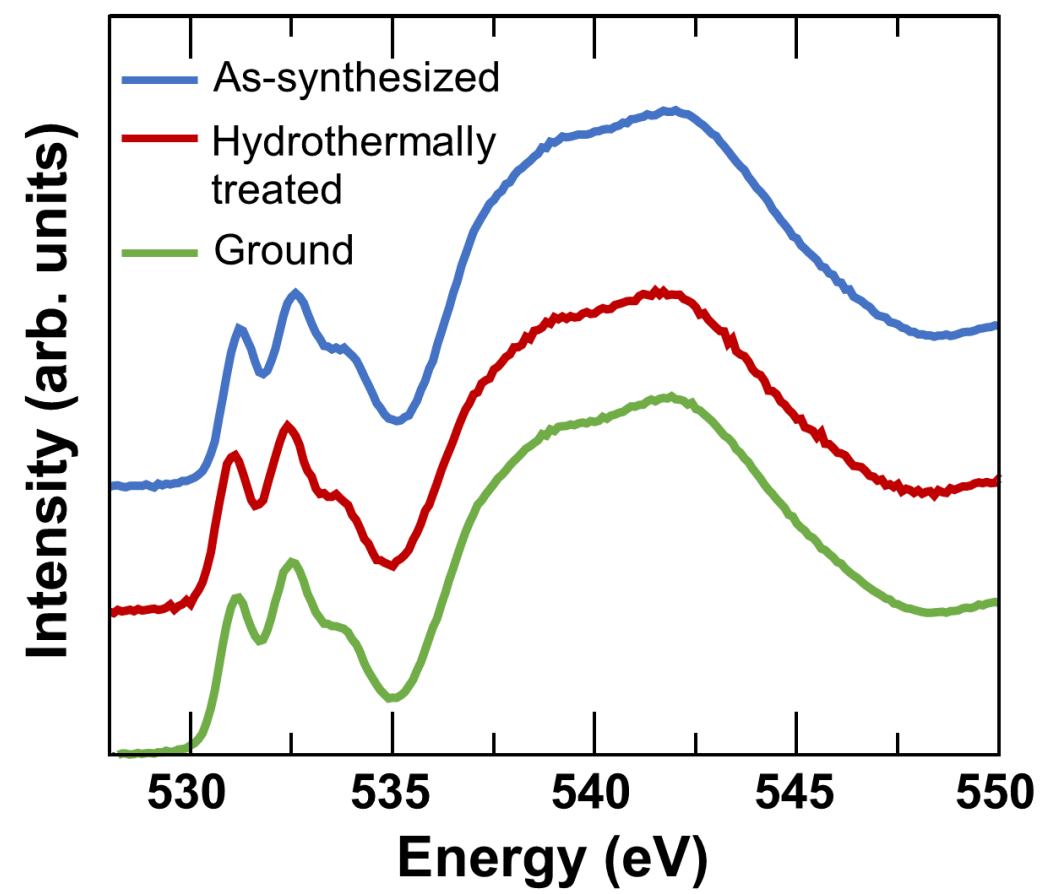

Figure S11. O K-edge XAS of goethite after sequential hydrothermal/grinding treatments. 


\section{Calculated linear combination fit of O K-edge XANES spectra}

In goethite there are two different environments for the oxygen atoms such that one of the oxygen sites is bounded to three iron atoms, while the other is in a tetrahedral site, linked to three iron atoms and one hydrogen atom. The two oxygen sites are involved in an $\mathrm{O} \cdots \mathrm{H}-\mathrm{O}$ hydrogen bond interaction with each other. The oxygen site linked to a hydrogen atom will be referred as "OH", while the other will be referred as "O". We used the linear combination of these two theoretically calculated contributions to reproduce the experimental O K-edge spectra of goethite samples under different experimental conditions.

Figure S12a shows that a good agreement can be obtained between the experimental spectra and the linear combination (LC) of the $\mathrm{O}$ K-edge spectra from the two oxygen sites. Especially, the intensity ratio between the peaks 2 and 3 in the calculated LC are very well reproduced for each case. Figures $\mathbf{S 1 2}(\mathbf{c}-\mathbf{e})$ show that the spectra from the $\mathrm{O}$ site are the main contributions to the lower energy peaks 1 and 2, while the $\mathrm{OH}$ site is the dominant contribution to the higher energy peak 3. For the as-synthesized goethite, shown in Figure S12c, the calculated relative area contribution from $\mathrm{O}$ and $\mathrm{OH}$ sites is $52.5 \%$ and $47.5 \%$ respectively, which is in good agreement with previous work ${ }^{7}$ using a doublet composed of two Gaussian functions for the $\mathrm{O}$ and $\mathrm{OH}$ components to reproduce the experimental spectra of goethite, and not too far away from the ideal $50 \%$ for each site type. 

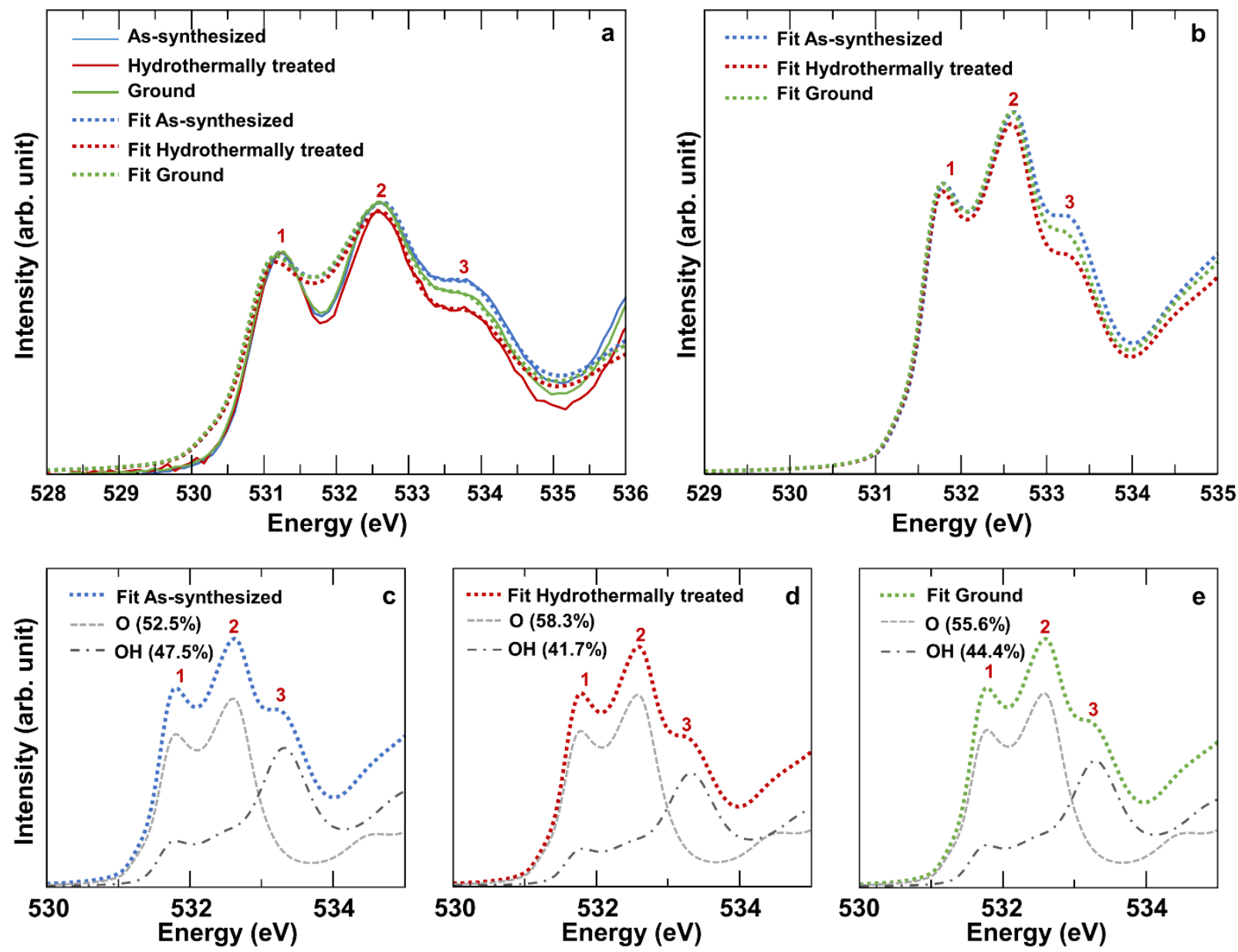

Figure S12. (a) Comparison between experimental goethite samples and calculated O K-edge spectra obtained by linear combination (LC) of $\mathrm{O}$ and $\mathrm{OH}$ components. The spectra have been linearly expanded in energy to allow a better comparison with the experimental spectra. (b) Unmodified calculated $\mathrm{O} \mathrm{K}$-edge spectra from linear combination. (c-e) Individual $\mathrm{O}$ and $\mathrm{OH}$ components in the linear combination of each case considered. 
Table S1. Mössbauer parameters derived from fitting spectra collected at $77 \mathrm{~K}$ for $1 \mathrm{mM}{ }^{5} \mathrm{Fe}(\mathrm{II})$ reacted with goethite after sequential hydrothermal/grinding treatments in addition to oxidized and $\mathrm{HCl}$-extracted samples.

\begin{tabular}{|c|c|c|c|c|c|c|c|c|}
\hline \multirow{3}{*}{ Sample } & \multirow[b]{2}{*}{ Experiment } & & \multicolumn{6}{|c|}{ Mössbauer parameters } \\
\hline & & & Component & & $\mathbf{Q S}^{\mathbf{b}}$ & & $\operatorname{Std}(H)$ or $\operatorname{Std}(Q S)^{d}$ & \\
\hline & & & & & & & & \\
\hline \multirow{25}{*}{$\begin{array}{l}{ }^{56} \mathrm{Fe} \text { As- } \\
\text { synthesized } \\
\text { goethite + 1mM } \\
{ }^{57} \mathrm{Fe}(\text { II })\end{array}$} & Batch \# & 2 & $\mathrm{Fe}(\mathrm{II})$ & 1.17 & 2.68 & & 0.35 & 2.2 \\
\hline & Initial Fe(II) & $1.15 \mathrm{mM}$ & Fe(III) Sextet 1 & 0.47 & -0.16 & 49.0 & 1.02 & 59.1 \\
\hline & Sorbed Fe(II) & $188 \mu$ moles $\mathrm{g}^{-1}$ & Fe(III) Sextet 2 & 0.51 & 0.07 & 49.0 & 1.29 & 29.6 \\
\hline & Rel. Area sextets & $88.7 \%$ & Collapsed Feature & $0.65^{\mathrm{e}}$ & $-0.10^{\mathrm{e}}$ & $25.8^{\mathrm{e}}$ & $14.65^{\mathrm{e}}$ & 9.2 \\
\hline & Batch \# & 3 & $\mathrm{Fe}(\mathrm{II})$ & 1.22 & 2.62 & & 0.41 & 2.0 \\
\hline & Initial Fe(II) & $1.063 \mathrm{mM}$ & Fe(III) Sextet 1 & 0.48 & -0.16 & 49.1 & 0.94 & 56.7 \\
\hline & Sorbed Fe(II) & $139 \mu$ moles $\mathrm{g}^{-1}$ & Fe(III) Sextet 2 & 0.51 & 0.07 & 49.3 & 1.19 & 29.1 \\
\hline & Rel. Area sextets & $85.8 \%$ & Collapsed Feature & $0.65^{\mathrm{e}}$ & $-0.10^{\mathrm{e}}$ & $25.8^{\mathrm{e}}$ & $14.65^{\mathrm{e}}$ & 12.2 \\
\hline & Oxidized sample & & Fe(III) Sextet 1 & 0.47 & -0.17 & 48.6 & 0.91 & 61.9 \\
\hline & Rel. Area sextets & $100.0 \%$ & Fe(III) Sextet 2 & 0.51 & 0.03 & 48.8 & 0.96 & 38.1 \\
\hline & \multirow{2}{*}{\multicolumn{2}{|c|}{ After $\mathrm{HCl}$ extraction }} & Fe(III) Sextet 1 & 0.48 & -0.15 & 48.3 & 0.90 & 45.4 \\
\hline & & & Fe(III) Sextet 2 & 0.50 & 0.06 & 48.5 & 0.99 & 29 \\
\hline & Rel. Area sextets & $100.0 \%$ & Fe(III) Sextet 3 & 0.45 & -0.37 & 47.1 & 0.95 & 25.5 \\
\hline & \multirow{3}{*}{\multicolumn{2}{|c|}{$\begin{array}{l}\text { Sequential } \\
\text { extractions } \\
\text { Buffer wash }\end{array}$}} & $\mathbf{F e}(\mathrm{II})$ & 1.18 & 2.63 & & 0.28 & 1.0 \\
\hline & & & Fe(III) Sextet 1 & 0.48 & -0.16 & 48.9 & 1.02 & 61.6 \\
\hline & & & Fe(III) Sextet 2 & 0.53 & 0.09 & 48.9 & 0.25 & 28.4 \\
\hline & Rel. Area sextets & $90.0 \%$ & Collapsed Feature & $0.65^{\mathrm{e}}$ & $-0.10^{\mathrm{e}}$ & $25.4^{\mathrm{e}}$ & $13.23^{\mathrm{e}}$ & 9.0 \\
\hline & \multirow{3}{*}{\multicolumn{2}{|c|}{$\begin{array}{l}\text { Sequential } \\
\text { extractions } \\
\mathrm{CaCl}_{2}\end{array}$}} & $\mathrm{Fe}(\mathrm{II})$ & 1.13 & 2.79 & & 0.18 & 0.8 \\
\hline & & & Fe(III) Sextet 1 & 0.48 & -0.16 & 48.9 & 1.04 & 63.4 \\
\hline & & & Fe(III) Sextet 2 & 0.52 & 0.07 & 49.0 & 1.27 & 29.1 \\
\hline & Rel. Area sextets & $92.5 \%$ & Collapsed Feature & $0.65^{\mathrm{e}}$ & $-0.10^{\mathrm{e}}$ & $25.8^{\mathrm{e}}$ & $14.65^{\mathrm{e}}$ & 6.7 \\
\hline & \multirow{3}{*}{\multicolumn{2}{|c|}{$\begin{array}{l}\text { Sequential } \\
\text { extractions } \\
\mathrm{NaH}_{2} \mathrm{PO}_{4}\end{array}$}} & $\mathrm{Fe}(\mathrm{II})$ & $1.20^{\mathrm{e}}$ & $2.70^{\mathrm{e}}$ & & $0.50^{\mathrm{e}}$ & 0.6 \\
\hline & & & Fe(III) Sextet 1 & 0.48 & -0.18 & 49 & 1.20 & 64.0 \\
\hline & & & Fe(III) Sextet 2 & 0.51 & $0.08^{\mathrm{e}}$ & 49.1 & 1.35 & 30.5 \\
\hline & Rel. Area sextets & $94.5 \%$ & Collapsed Feature & $0.65^{\mathrm{e}}$ & $-0.10^{\mathrm{e}}$ & $25.4^{\mathrm{e}}$ & $13.23^{\mathrm{e}}$ & 4.8 \\
\hline
\end{tabular}


Mössbauer parameters

\begin{tabular}{|c|c|c|c|c|c|c|c|c|}
\hline \multirow[b]{2}{*}{ Sample } & \multirow{2}{*}{\multicolumn{2}{|c|}{ Experiment }} & \multirow[b]{2}{*}{ Component } & \multirow{3}{*}{$\begin{array}{c}\begin{array}{c}\mathbf{C S}^{\mathbf{a}} \\
\left(\mathrm{mm} \mathrm{s}^{-1}\right)\end{array} \\
1.17\end{array}$} & \multirow{3}{*}{$\begin{array}{c}\mathbf{Q S}^{\mathbf{b}} \\
\left(\mathrm{mm} \mathrm{s}^{-1}\right)\end{array}$} & \multirow[b]{2}{*}{$\begin{array}{c}\mathbf{H}^{\mathbf{c}} \\
(\text { Tesla })\end{array}$} & \multirow{3}{*}{$\begin{array}{c}\operatorname{Std}(\mathbf{H}) \text { or } \mathbf{S t d}(\mathbf{Q S})^{\mathbf{d}} \\
\left(\text { Tesla) or }\left(\mathrm{mm} \mathrm{s}^{-1}\right)\right. \\
0.35\end{array}$} & \multirow{3}{*}{$\begin{array}{l}\text { Area } \\
(\%) \\
2.4\end{array}$} \\
\hline & & & & & & & & \\
\hline \multirow{12}{*}{$\begin{array}{l}{ }^{56} \mathrm{Fe} \\
\text { Hydrothermally } \\
\text { treated goethite + } \\
1 \mathrm{mM}{ }^{57} \mathrm{Fe}(\mathrm{II})\end{array}$} & Batch \# & 2 & $\mathrm{Fe}(\mathrm{II})$ & & & & & \\
\hline & Initial Fe(II) & $1.14 \mathrm{mM}$ & Fe(III) Sextet 1 & 0.47 & -0.17 & 48.7 & 1.01 & 41.2 \\
\hline & Sorbed Fe(II) & $136 \mu$ moles $\mathrm{g}^{-1}$ & Fe(III) Sextet 2 & 0.51 & 0.09 & 49.2 & 1.13 & 24.0 \\
\hline & Rel. Area sextets & $65.2 \%$ & Collapsed Feature & $0.65^{\mathrm{e}}$ & $-0.10^{\mathrm{e}}$ & $25.8^{\mathrm{e}}$ & $14.65^{\mathrm{e}}$ & 32.4 \\
\hline & Batch \# & 3 & $\mathrm{Fe}(\mathrm{II})$ & 1.21 & 2.88 & & 0.41 & 3.1 \\
\hline & Initial Fe(II) & $1.132 \mathrm{mM}$ & Fe(III) Sextet 1 & 0.48 & -0.17 & 48.9 & 1.10 & 39.4 \\
\hline & Sorbed Fe(II) & $122 \mu$ moles $\mathrm{g}^{-1}$ & Fe(III) Sextet 2 & 0.49 & 0.06 & 1.25 & 1.25 & 26.9 \\
\hline & Rel. Area sextets & $66.3 \%$ & Collapsed Feature & $0.65^{\mathrm{e}}$ & $-0.10^{e}$ & $25.8^{\mathrm{e}}$ & $14.65^{\mathrm{e}}$ & 30.6 \\
\hline & & & $\mathbf{F e}(\mathrm{II})$ & 1.20 & 2.70 & & 0.50 & 0.1 \\
\hline & Oxidized sample & & Fe(III) Sextet 1 & 0.48 & -0.17 & 48.3 & 1.06 & 55.8 \\
\hline & & & Fe(III) Sextet 2 & 0.48 & 0.04 & 48.7 & 1.21 & 36.6 \\
\hline & Rel. Area sextets & $92.4 \%$ & Collapsed Feature & $0.65^{\mathrm{e}}$ & $-0.10^{\mathrm{e}}$ & $25.8^{\mathrm{e}}$ & $14.65^{\mathrm{e}}$ & 7.5 \\
\hline \multirow{11}{*}{$\begin{array}{l}{ }^{56} \mathrm{Fe} \text { Ground } \\
\text { goethite + 1mM } \\
{ }^{57} \mathrm{Fe}(\mathrm{II})\end{array}$} & Batch \# & 3 & $\mathbf{F e}(\mathbf{I I})$ & 1.22 & 2.81 & & 0.49 & 3.1 \\
\hline & Initial Fe(II) & $1.104 \mathrm{mM}$ & Fe(III) Sextet 1 & 0.48 & -0.16 & 49.0 & 1.13 & 51.8 \\
\hline & Sorbed Fe(II) & $106 \mu$ moles $\mathrm{g}^{-1}$ & Fe(III) Sextet 2 & 0.50 & 0.07 & 49.4 & 1.40 & 30.1 \\
\hline & Rel. Area sextets & $81.9 \%$ & Collapsed Feature & $0.65^{\mathrm{e}}$ & $-0.1^{\mathrm{e}}$ & $25.8^{\mathrm{e}}$ & $14.65^{\mathrm{e}}$ & 15.0 \\
\hline & Batch \# & 3 & $\mathbf{F e}(\mathbf{I I})$ & 1.22 & 2.70 & & 0.53 & 3.2 \\
\hline & Initial Fe(II) & $1.123 \mathrm{mM}$ & Fe(III) Sextet 1 & 0.48 & -0.17 & 48.9 & 1.13 & 48.9 \\
\hline & Sorbed Fe(II) & 99 & Fe(III) Sextet 2 & 0.49 & 0.07 & 49.4 & 1.39 & 31.0 \\
\hline & Rel. Area sextets & $79.9 \%$ & Collapsed Feature & $0.65^{\mathrm{e}}$ & $-0.10^{\mathrm{e}}$ & $25.8^{\mathrm{e}}$ & $14.65^{\mathrm{e}}$ & 16.9 \\
\hline & \multirow{2}{*}{ Oxidized sample } & & Fe(III) Sextet 1 & 0.48 & -0.21 & 48.8 & 1.30 & 50.5 \\
\hline & & & Fe(III) Sextet 2 & 0.49 & 0.02 & 49.0 & 1.40 & 46.5 \\
\hline & Rel. Area sextets & $97 \%$ & Collapsed Feature & $0.65^{\mathrm{e}}$ & $-0.10^{\mathrm{e}}$ & $25.8^{\mathrm{e}}$ & $14.7^{\mathrm{e}}$ & 3.0 \\
\hline${ }^{56} \mathrm{Fe}$ & Batch \# & 3 & $\mathrm{Fe}(\mathrm{II})$ & 1.21 & 2.71 & & 0.51 & 7.7 \\
\hline \multirow{3}{*}{$\begin{array}{l}\text { Hydrothermally } \\
\text { treated again } \\
\text { goethite + 1mM } \\
{ }^{57} \mathrm{Fe}(\mathrm{II})\end{array}$} & Initial Fe(II) & $1.222 \mathrm{mM}$ & Fe(III) Sextet 1 & 0.47 & -0.17 & 48.3 & 1.06 & 38.3 \\
\hline & Sorbed Fe(II) & $102 \mu$ moles g $^{-1}$ & Fe(III) Sextet 2 & 0.48 & 0.08 & 48.9 & 1.11 & 23.8 \\
\hline & Rel. Area sextets & $62.1 \%$ & Collapsed Feature & $0.65^{\mathrm{e}}$ & $-0.10^{\mathrm{e}}$ & $25.8^{\mathrm{e}}$ & $14.65^{\mathrm{e}}$ & 30.3 \\
\hline
\end{tabular}


Mössbauer parameters

\begin{tabular}{|c|c|c|c|c|c|c|c|c|}
\hline \multirow[t]{8}{*}{ Sample } & \multicolumn{2}{|l|}{ Experiment } & Component & \multirow{2}{*}{$\begin{array}{c}\begin{array}{c}\mathbf{C S}^{\mathbf{a}} \\
\left(\mathrm{mm} \mathrm{s}^{-1}\right)\end{array} \\
1.25\end{array}$} & \multirow{2}{*}{$\begin{array}{c}\begin{array}{c}\mathbf{Q S}^{\mathbf{b}} \\
\left(\mathrm{mm} \mathrm{s}^{-1}\right)\end{array} \\
2.91\end{array}$} & \multirow[t]{2}{*}{$\begin{array}{c}\mathbf{H}^{\mathbf{c}} \\
\text { (Tesla) } \\
\end{array}$} & \multirow{2}{*}{$\begin{array}{c}\operatorname{Std}(\mathbf{H}) \text { or } \operatorname{Std}(\mathbf{Q S})^{\mathbf{d}} \\
\left(\text { Tesla) or }\left(\mathrm{mm} \mathrm{s}^{-1}\right)\right.\end{array}$} & \multirow{2}{*}{$\begin{array}{c}\begin{array}{c}\text { Area } \\
(\%)\end{array} \\
7.5\end{array}$} \\
\hline & Batch \# & 3 & $\mathrm{Fe}(\mathrm{II})$ & & & & & \\
\hline & Initial Fe(II) & $1.078 \mathrm{mM}$ & Fe(III) Sextet 1 & 0.48 & -0.16 & 48.7 & 1.09 & 39.6 \\
\hline & Sorbed Fe(II) & $81 \mu$ moles $\mathrm{g}^{-1}$ & Fe(III) Sextet 2 & 0.49 & 0.09 & 49.4 & 1.26 & 24.1 \\
\hline & Rel. Area sextets & $63.7 \%$ & Collapsed Feature & $0.65^{\mathrm{e}}$ & $-0.10^{\mathrm{e}}$ & $26.25^{\mathrm{e}}$ & $13.75^{\mathrm{e}}$ & 28.7 \\
\hline & \multirow{2}{*}{\multicolumn{2}{|c|}{ Oxidized sample }} & Fe(III) Sextet 1 & 0.49 & -0.20 & 48.6 & 1.35 & 45.3 \\
\hline & & & Fe(III) Sextet 2 & 0.48 & 0.04 & 48.9 & 1.43 & 44.4 \\
\hline & Rel. Area sextets & $89.7 \%$ & Collapsed Feature & $0.64^{\mathrm{e}}$ & $-0.10^{\mathrm{e}}$ & $25.8^{\mathrm{e}}$ & $14.65^{\mathrm{e}}$ & 10.3 \\
\hline
\end{tabular}

Center shift

'Quadrupole splitting for doublets and quadrupole shift parameter for sextets

Hyperfine Field

¿Standards deviation of the Voigt profile for the hyperfine field or quadrupole splitting parameters, respectively

${ }^{\mathrm{e}}$ Denotes that the parameter was fixed 
Table S2. Fe(II) and Fe total extraction data.

\begin{tabular}{lccc}
\hline Step & Fe(II) $)_{\text {aq }}(\boldsymbol{\mu m o l})$ & Fe(tot) $(\boldsymbol{\mu m o l})$ & \% of sorbed Fe(II) recovered \\
\hline 0.4 M HCl extraction & & & \\
Initial aqueous & 892 & 891 & \\
Final ${ }_{\text {aqueous }}$ & 591 & 305 & 100 \\
$\mathrm{HCl}_{\text {extracted }}$ & 303 & & \\
Sequential extractions & & & \\
Initial $_{\text {aqueous }}$ & 1120 & 750 & 22 \\
Final $_{\text {aqueous }}$ & 760 & 70 & 17 \\
$\mathrm{Buffer}_{\text {wash }}$ extracted & 80 & 50 & 39 \\
$\mathrm{CaCl}_{2 \text { extracted }}$ & 60 & 140 & \\
$\mathrm{NaH}_{2} \mathrm{PO}_{4}$ extracted & 140 & & \\
\end{tabular}


Table S3. Characteristics of goethite after sequential hydrothermal/grinding treatments.

\begin{tabular}{|c|c|c|c|c|}
\hline & \multicolumn{3}{|c|}{ XRD Cell dimensions } & \multirow{2}{*}{$\frac{\text { BET }}{\left(\mathrm{m}^{2} \mathrm{~g}^{-1}\right)}$} \\
\hline & $a(\AA)$ & $b(\AA)$ & $c(\AA)$ & \\
\hline As-synthesized & 4.606 & 9.964 & 3.027 & 28 \\
\hline Hydrothermally treated & 4.606 & 9.955 & 3.023 & 26 \\
\hline Ground & 4.605 & 9.955 & 3.022 & 18 \\
\hline Hydrothermally treated again & 4.603 & 9.956 & 3.022 & 19 \\
\hline
\end{tabular}




\section{References}

1. Amstaetter, K.; Borch, T.; Larese-Casanova, P.; Kappler, A., Redox Transformation of Arsenic by Fe(II)-Activated Goethite ( $\alpha$-FeOOH). Environmental Science \& Technology 2010, $44,(1), 102-108$.

2. Pasakarnis, T.; McCormick, M. L.; Parkin, G. F.; Thompson, A.; Scherer, M. M., Fe ${ }^{\mathrm{II}}$ aq$\mathrm{Fe}^{\mathrm{III}}$ oxide electron transfer and $\mathrm{Fe}$ exchange: effect of organic carbon. Environmental Chemistry 2015, 12, (1), 52-63.

3. Latta, D. E.; Bachman, J. E.; Scherer, M. M., Fe Electron Transfer and Atom Exchange in Goethite: Influence of Al-Substitution and Anion Sorption. Environmental Science \& Technology 2012, 46, (19), 10614-10623.

4. Genin, J. M.; Bauer, P.; Olowe, A. A.; Rezel, D., Mössbauer study of the kinetics of simulated corrosion process of iron in chlorinated aqueous solution around room temperature: The hyperfine structure of ferrous hydroxides and Green Rust I. Hyperfine Interactions 1986, 29, (1), 1355-1360.

5. Burns, R. G., Intervalence transitions in mixed valence minerals of iron and titanium. Annual Review of Earth and Planetary Sciences 1981, 9, (1), 345-383.

6. Yoshida, Y.; Langouche, G., Mössbauer Spectroscopy: Tutorial Book. Springer Berlin Heidelberg: 2012.

7. Gilbert, B.; Erbs, J. J.; Penn, R. L.; Petkov, V.; Spagnoli, D.; Waychunas, G. A., A disordered nanoparticle model for 6-line ferrihydrite. American Mineralogist 2013, 98, (8-9), 1465-1476. 